\title{
ChABC infusions into medial prefrontal cortex, but not posterior parietal cortex, improve the performance of rats tested on a novel, challenging delay in the touchscreen TUNL task
}

\author{
Michael D. Anderson, ${ }^{1}$ John W. Paylor, ${ }^{2}$ Gavin A. Scott, ${ }^{1}$ Quentin Greba, ${ }^{1}$ Ian R. Winship, ${ }^{2}$ \\ and John G. Howland ${ }^{1}$ \\ ${ }^{1}$ Department of Anatomy, Physiology and Pharmacology University of Saskatchewan, Saskatoon, Saskatchewan S7N 5E5, Canada; \\ ${ }^{2}$ Department of Psychiatry, University of Alberta, Edmonton, Alberta T6G 2B7, Canada
}

Perineuronal nets (PNNs) are specialized extracellular matrix structures that surround subsets of neurons throughout the central nervous system (CNS). They are made up of chondroitin sulfate proteoglycans (CSPGs), hyaluronan, tenascin-R, and many other link proteins that together make up their rigid and lattice-like structure. Modulation of PNNs can alter synaptic plasticity and thereby affect learning, memory, and cognition. In the present study, we degraded PNNs in the medial prefrontal ( $\mathrm{mPFC}$ ) and posterior parietal (PPC) cortices of Long-Evans rats using the enzyme chondroitinase $A B C$ (ChABC), which cleaves apart CSPGs. We then measured the consequences of PNN degradation on spatial working memory (WM) with a trial-unique, non-matching-to location (TUNL) automated touchscreen task. All rats were trained with a standard $6 \mathrm{sec}$ delay and 20 sec inter-trial interval (ITI) and then tested under four different conditions: a 6 sec delay, a variable 2 or 6 sec delay, a 2 sec delay with a $1 \mathrm{sec}$ ITI (interference condition), and a 20 sec delay. Rats that received $\mathrm{mPFC} C \mathrm{ChABC}$ treatment initially performed TUNL with higher accuracy, more selection trials completed, and fewer correction trials completed compared to controls in the 20 sec delay condition but did not perform differently from controls in any other condition. Rats that received PPC ChABC treatment did not perform significantly differently from controls in any condition. Posthumous immunohistochemistry confirmed an increase in CSPG degradation products (C4S stain) in the mPFC and PPC following ChABC infusions while WFA staining intensity and parvalbumin positive neuron number were decreased following $\mathrm{mPFC}$, but not PPC, ChABC infusions. These findings suggest that PNNs in the mPFC play a subtle role in spatial WM, but PNNs in the PPC do not. Furthermore, it appears that PNNs in the $\mathrm{mPFC}$ are involved in adapting to a challenging novel delay, but that they do not play an essential role in spatial WM function.

\begin{abstract}
PNNs are part of the extracellular matrix (ECM) of the central nervous system (CNS). They are composed of chondroitin sulfate proteoglycans (CSPGs), hyaluronan, tenascin-R, and many link proteins, which make up their rigid matrix structure (Deepa et al. 2006). While discrete patterns of PNN distribution vary between species (Lensjø et al. 2017a), their conserved appearance suggest that they play an integral and important role in the CNS. PNNs act as a physical barrier to structural changes in the neurons that they surround (Kwok et al. 2010). In addition, PNNs are involved in synaptic stabilization and in the closure of critical periods of plasticity during development (Pizzorusso et al. 2002). The density of PNNs is relatively low early in development and increases throughout postnatal life (Sorg et al. 2016). Related to this, the removal of PNNs in adulthood can reopen periods of heightened plasticity comparable to that of a juvenile critical period (Lensjø et al. 2017b). With such heightened plasticity comes potential reorganization of neuronal structure, connectivity, and function (Pizzorusso et al. 2002).

PNNs appear involved with learning and memory in the adult brain, and PNN degradation in the brain changes behavior and
\end{abstract}

Corresponding author: john.howland@usask.ca Article is online at http://www.learnmem.org/cgi/doi/10.1101/lm.050245.119. cognition (Gogolla et al. 2009; Lee et al. 2012; Hylin et al. 2013; Happel et al. 2014; Xue et al. 2014; Lasek et al. 2018; Paylor et al. 2018; Thompson et al. 2018; Domínguez et al. 2019). A common method of degrading PNNs is by targeting CSPGs with the enzyme chondroitinase ABC (ChABC; Lee et al. 2009). Interestingly, the cognitive and behavioral changes following ChABC infusions depend on the location and timing of treatment (Shen 2018). For example, the infusion of ChABC into the perirhinal cortex enhances recognition memory in an object recognition paradigm (Romberg et al. 2013). In contrast, infusion of ChABC into the medial prefrontal cortex (mPFC) impairs cross-modal object recognition and object oddity tests in rats (Paylor et al. 2018). Reductions in cortical PNNs are also observed in human patients with schizophrenia and Alzheimer's disease (Baig et al. 2005; Mauney et al. 2013; Enwright et al. 2016) and in animal models of stroke, prion diseases, epilepsy, and schizophrenia (Hobohm et al. 2005; Franklin et al. 2008; McRae and Porter 2012; Paylor

\footnotetext{
D 2020 Anderson et al. This article is distributed exclusively by Cold Spring Harbor Laboratory Press for the first 12 months after the full-issue publication date (see http://learnmem.cshlp.org/site/misc/terms.xhtml). After 12 months, it is available under a Creative Commons License (Attribution-NonCommercial 4.0 International), as described at http://creativecommons.org/licenses/by-nc/ $4.0 \%$
} 


\begin{tabular}{|c|c|c|c|c|c|}
\hline $\begin{array}{c}\text { TUNL Pretraining } \\
(35-50 \text { days })\end{array}$ & $\begin{array}{c}\text { Surgery } \\
(5-10 \text { days })\end{array}$ & $\begin{array}{c}\text { Condition 1 } \\
6 \text { s delay } \\
3 \text { days }\end{array}$ & $\begin{array}{c}\text { Condition 2 or 6s delay } \\
4 \text { days }\end{array}$ & $\begin{array}{c}\text { Condition 3 } \\
1 \mathrm{~s} \mathrm{ITI} \\
2 \text { days }\end{array}$ & $\begin{array}{c}\text { Condition 4 } \\
20 \text { delay } \\
6 \text { days }\end{array}$ \\
\hline
\end{tabular}

Figure 1. Schematic of the training and testing schedule. During the training phase, rats were trained on TUNL to criterion. Chondroitinase $A B C$ or penicillinase was then locally infused into medial prefrontal cortex or posterior parietal cortex. Following recovery, all rats were tested on four conditions in the following order: Condition (1) their performance was reassessed for $3 \mathrm{~d}$ on the standard TUNL task that they were trained on presurgery; Condition (2) a variable delay 2 or 6 sec delay was used to assess WM; Condition (3) was designed as an interference task with a $1 \mathrm{sec}$, instead of the standard $20 \mathrm{sec}$, ITI between trials; and Condition (4) introduced a novel and challenging delay of $20 \mathrm{sec}$.

et al. 2016). Continued investigation of how PNNs contribute to cognition in adults will help us to discover whether there is a link between abnormalities in PNN distribution and the cognitive deficits seen in these CNS disorders.

In the current study, the spatial working memory (WM) of Long-Evans rats was tested following the degradation of PNNs in the mPFC and posterior parietal cortex (PPC). Spatial WM was measured using the automated touchscreenbased trial-unique, non-matching-to location (TUNL) task, which was chosen because it is clinically translatable, requires little handling of animals during testing, and gives an accurate measure of task parameters (Talpos et al. 2010). Performance of the TUNL task relies on the mPFC and the PPC in rats (McAllister et al. 2013; Davies et al. 2017; Scott et al. 2019). Likewise, it has been suggested that the human prefrontal cortex and PPC are essential for functional spatial $\mathrm{WM}$, and that $\mathrm{WM}$ relies on intact fronto-parietal circuits (Courtney et al. 1998; Todd and Marois 2004; Eriksson et al. 2015; Alekseichuk et al. 2016; Mackey et al. 2016). In our previous study, ChABC infusions into the mPFC led to cognitive impairments (Paylor et al. 2018). Based on these findings, we hypothesized that the degradation of PNNs in the mPFC and PPC would disrupt the neural circuits required for spatial WM and impair the performance of rats in the TUNL task.

\section{Results}

Rats were trained on the TUNL task (Figs. $1,2)$ until they reached a group mean of 50 trials at $65 \%$ accuracy using a 6 sec delay. Infusions of either penicillinase (PEN) as a control or ChABC to degrade CSPGs were made into the mPFC of one cohort of rats and into the PPC of another cohort of rats. After 5-10 d of recovery, rats were tested in TUNL using four different conditions: a 6 sec delay, a variable 2 or 6 sec delay, a 2 sec delay with a $1 \mathrm{sec}$ inter-trial interval (ITI) period (inter-
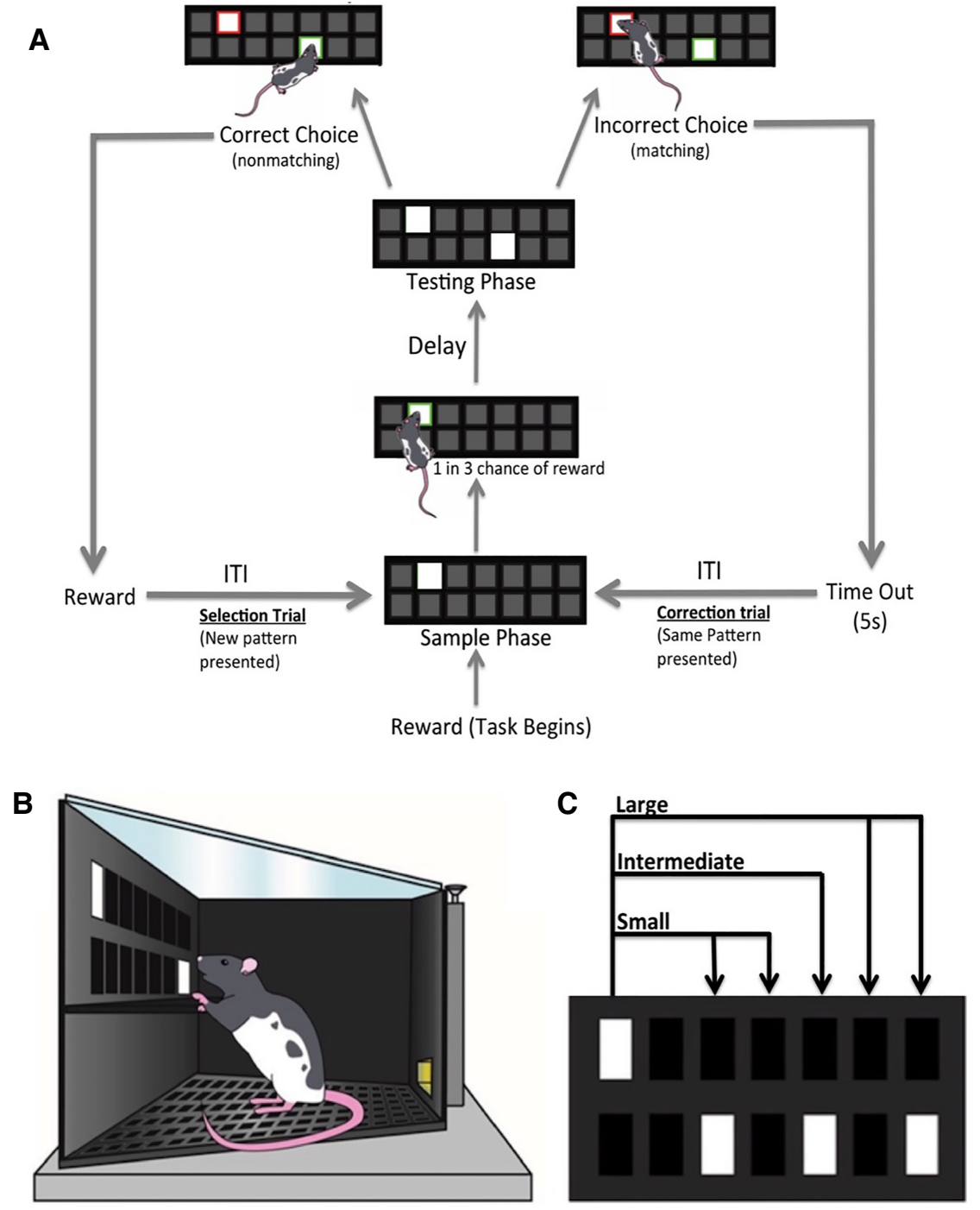

Figure 2. (A) Schematic showing the progression of a TUNL trial. The standard TUNL task for training involves a $6 \mathrm{sec}$ delay and a $20 \mathrm{sec} \mathrm{ITI}$, but the length of both of these periods can be altered. (B) Schematic of a Long-Evans rat performing the testing phase of the TUNL task. (C) Schematic labeling distances between stimuli in the testing phase as large (4-5 squares away), intermediate ( 3 squares away), or small (1-2 squares away). Stimuli within the testing phase of a trial are not presented horizontally, vertically, or diagonally adjacent to one another. 
Table 1. Performance of the rats on testing conditions 1,2 , and 3 of the experiment

\begin{tabular}{|c|c|c|c|c|c|}
\hline Condition & Accuracy-Large & Accuracy-Small & Total trials & Selection trials & Correction trials \\
\hline \multicolumn{6}{|l|}{ mPFC } \\
\hline 1 (6 sec delay, $20 \mathrm{sec}$ ITI) & $\begin{array}{l}\text { PEN, } 76.80 \pm 9.4 \\
\text { Ch, } 77.28 \pm 7.9 \\
M E, L g>S m\end{array}$ & $\begin{array}{l}\text { PEN, } 62.61 \pm 5.7 \\
\text { Ch, } 62.1 \pm 8.9\end{array}$ & $\begin{array}{l}\text { PEN, } 84.90 \pm 6.2 \\
\text { Ch, } 82.64 \pm 11.4\end{array}$ & $\begin{array}{l}\text { PEN, } 58.95 \pm 5.4 \\
\text { Ch, } 56.48 \pm 11.5\end{array}$ & $\begin{array}{l}\text { PEN, } 25.94 \pm 4.9 \\
\text { Ch, 26.15 } \pm 3.3\end{array}$ \\
\hline 2 (2 sec delay) & $\begin{array}{l}\text { PEN, } 86.32 \pm 6.4 \\
\text { Ch, } 85.31 \pm 4.0 \\
\text { Int, see text }\end{array}$ & $\begin{array}{l}\text { PEN, } 68.43 \pm 8.5 \\
\text { Ch, } 69.43 \pm 7.9\end{array}$ & $\begin{array}{l}\text { PEN, } 94.17 \pm 9.6 \\
\text { Ch, } 89.18 \pm 10.6\end{array}$ & $\begin{array}{l}\text { PEN, } 69.43 \pm 5.9 \\
\text { Ch, } 64.95 \pm 8.9\end{array}$ & $\begin{array}{l}\text { PEN, } 24.73 \pm 5.9 \\
\text { Ch, } 24.23 \pm 4.9\end{array}$ \\
\hline 2 (6 sec delay) & $\begin{array}{l}\text { PEN, } 57.65 \pm 6.1 \\
\text { Ch, } 59.40 \pm 7.8 \\
\text { Int, see text }\end{array}$ & $\begin{array}{l}\text { PEN, } 67.61 \pm 6.9 \\
\text { Ch, } 67.77 \pm 6.5\end{array}$ & & & \\
\hline 3 ( 2 sec delay, $1 \mathrm{sec}$ ITI) & $\begin{array}{l}\text { PEN, } 85.92 \pm 7.1 \\
\mathrm{Ch}, 82.98 \pm 7.2 \\
\mathrm{ME}, \mathrm{Lg}>\mathrm{Sm}\end{array}$ & $\begin{array}{l}\text { PEN, } 64.36 \pm 7.1 \\
\text { Ch, } 67.68 \pm 6.1\end{array}$ & $\begin{array}{l}\text { PEN, } 110.63 \pm 8.3 \\
\text { Ch, } 112.45 \pm 12.7\end{array}$ & $\begin{array}{l}\text { PEN, } 81.04 \pm 7.6 \\
\text { Ch, } 81.80 \pm 6.8\end{array}$ & $\begin{array}{l}\text { PEN, } 29.58 \pm 7.1 \\
\text { Ch, } 29.33 \pm 8.7\end{array}$ \\
\hline \multicolumn{6}{|l|}{ PPC } \\
\hline 1 ( 6 sec delay, $20 \mathrm{sec}$ ITI) & $\begin{array}{l}\text { PEN, } 71.00 \pm 8.6 \\
\mathrm{Ch}, 63.55 \pm 9.4 \\
\mathrm{ME}, \mathrm{Lg}>\mathrm{Sm}\end{array}$ & $\begin{array}{l}\text { PEN, } 59.76 \pm 13.3 \\
\text { Ch, } 54.67 \pm 8.1\end{array}$ & $\begin{array}{l}\text { PEN, } 75.31 \pm 15.3 \\
\text { Ch, } 69.61 \pm 14.7\end{array}$ & $\begin{array}{l}\text { PEN, } 47.31 \pm 12.9 \\
\text { Ch, } 41.25 \pm 9.8\end{array}$ & $\begin{array}{l}\text { PEN, } 28.00 \pm 6.3 \\
\text { Ch, } 28.36 \pm 8.7\end{array}$ \\
\hline 2 (2 sec delay) & $\begin{array}{l}\text { PEN, } 78.03 \pm 12.2 \\
\text { Ch, } 77.85 \pm 9.2 \\
\text { Int, see text }\end{array}$ & $\begin{array}{l}\text { PEN, } 65.16 \pm 6.1 \\
\text { Ch, } 65.45 \pm 7.5\end{array}$ & $\begin{array}{l}\text { PEN, } 82.08 \pm 11.9 \\
\text { Ch, } 75.93 \pm 15.1\end{array}$ & $\begin{array}{l}\text { PEN, } 54.26 \pm 10.7 \\
\text { Ch, } 50.92 \pm 10.0\end{array}$ & $\begin{array}{l}\text { PEN, } 27.83 \pm 7.2 \\
\text { Ch, } 25.01 \pm 8.1\end{array}$ \\
\hline 2 (6 sec delay) & $\begin{array}{l}\text { PEN, } 53.76 \pm 7.5 \\
\text { Ch, } 53.56 \pm 12.2 \\
\text { Int, see text }\end{array}$ & $\begin{array}{l}\text { PEN, } 61.66 \pm 9.4 \\
\text { Ch, } 61.10 \pm 9.3\end{array}$ & & & \\
\hline 3 ( 2 sec delay, $1 \mathrm{sec}$ ITI) & $\begin{array}{l}\text { PEN, } 73.77 \pm 6.6 \\
\text { Ch, } 74.54 \pm 12.4 \\
M E, ~ L g>S m\end{array}$ & $\begin{array}{l}\text { PEN, } 62.84 \pm 11.6 \\
\text { Ch, } 65.21 \pm 7.8\end{array}$ & $\begin{array}{l}\text { PEN, } 103.00 \pm 16.3 \\
\text { Ch, } 92.08 \pm 14.3\end{array}$ & $\begin{array}{l}\text { PEN, } 71.00 \pm 14.8 \\
\text { Ch, } 62.92 \pm 11.5\end{array}$ & $\begin{array}{l}\text { PEN, } 32.00 \pm 8.9 \\
\text { Ch, } 29.17 \pm 10.9\end{array}$ \\
\hline
\end{tabular}

Group means \pm SEM are shown for dependent measures (columns) during the various testing conditions (rows) for rats infused with either ChABC (Ch) or PEN into the mPFC (top) and PPC (bottom). Note that accuracy of 50\% is chance performance in the TUNL task. ME refers to a main effect and Int to an interaction regarding Accuracy in the ANOVA. See Results for details.

Independent-samples $t$-tests revealed that ChABC-treated rats did not perform significantly differently from PEN-treated rats in terms of total trials completed (Table $1 ; t_{(21)}=0.60, P=$ 0.56 ), selection trials completed (Table $1 ; t_{(21)}=0.67, P=0.51$ ), correction trials completed (Table $1 ; t_{(21)}=-0.117, P=0.91$ ), or reward latency (Table $2 ; t_{(21)}=0.51, P=0.62$ ). A $2 \times 2$ ANOVA (treatment, latency type) revealed that there was no difference in the correct and incorrect trial latency of ChABC-treated versus PEN-treated rats (Table 2; $F_{(1,21)}=0.11, P=0.74$ ), but that the incorrect trial latency was significantly longer than the correct trial latency $\left(F_{(1,21)}=15.86, P=0.001\right)$. There was no significant interaction between treatment and latency type $\left(F_{(1,21)}=1.61\right.$, $P=0.22$ ).

\section{ChABC infusions in the mPFC had no effect on the performance of rats in condition 2 (variable 2 or 6 sec delay)}

A three-way ANOVA (treatment, separation, delay) revealed no significant differences in percent accuracy between ChABC and PEN-treated rats (Table $1 ; F_{(1,21)}=0.07, P=0.80$ ). However, main effects of separation $\left(F_{(1,21)}=8.64, P=0.008\right)$ and delay $\left(F_{(1,21)}=131.32, P<0.001\right)$ were found, as well as a significant interaction between the two factors $\left(F_{(1,21)}=87.12, P<0.001\right)$. Post hoc analyses (Tukey's) revealed that the percent accuracy on trials with a 2 sec delay and large stimulus separations was significantly higher than any other trial type $(P<0.05)$. In addition, the percent accuracy on trials with a 2 sec delay and small separations was not significantly different than that of trials with a $6 \mathrm{sec}$ delay and small separations $(P>0.05)$, but both were significantly higher than trials with a 6 sec delay and large separations $(P<0.05)$ (Table 1). There were no significant interactions between treatment and delay $\left(F_{(1,21)}=0.16, P=0.69\right)$, treatment and separation $\left(F_{(1,21)}=0.00, P=0.95\right)$, or treatment $\times$ delay $\times$ separation $\left(F_{(1,21)}=0.39, P=0.54\right)$.
Independent-samples $t$-tests revealed that ChABC-treated rats did not perform significantly differently from PEN-treated rats in terms of total trials completed (Table $1 ; t_{(21)}=1.18, P=0.25$ ), selection trials completed (Table $1 ; t_{(21)}=1.43, P=0.17$ ), correction trials completed (Table $1 ; t_{(21)}=0.22, P=0.83$ ), or reward latency (Table $\left.2 ; t_{(21)}=-0.272, P=0.79\right)$. A $2 \times 2$ repeated ANOVA (treatment, separation) revealed no significant difference in the correct and incorrect trial latency of ChABC-treated versus PEN-treated rats (Table $\left.2 ; F_{(1,21)}=0.81, P=0.38\right)$, but the incorrect trial latency was significantly longer than the correct trial latency $\left(F_{(1,21)}=16.17\right.$, $P=0.001)$. There was no significant interaction between treatment and latency type $\left(F_{(1,21)}=1.38, P=0.25\right)$.

\section{ChABC infusions in the mPFC had no effect on the performance of rats in condition 3 (2 sec delay with a 1 sec ITI)}

A $2 \times 2$ ANOVA (treatment, separation) revealed that the percent accuracy of ChABC-treated rats was not significantly different than that of PEN-treated rats (Table $1 ; F_{(1,21)}=0.00, P=0.94$ ). However, the percent accuracy of rats was significantly higher on large separation trials compared to small separation trials $\left(F_{(1,21)}=\right.$ $189.54, P<0.001)$, with a significant interaction between separation and treatment $\left(F_{(1,21)}=5.46, P=0.029\right)$. Independent-samples $t$-tests revealed that ChABC-treated rats did not perform significantly differently from PEN-treated rats in terms of total trials completed (Table $1 ; t_{(21)}=-0.41, P=0.68$ ), selection trials completed (Table $1 ; t_{(21)}=-0.33, P=0.75$ ), correction trials completed (Table $1 ; t_{(21)}=-0.27, P=0.79$ ), or reward latency (Table $2 ; t_{(21)}=-0.14$, $P=0.89)$. A $2 \times 2$ ANOVA revealed no significant difference in the correct and incorrect trial latency of ChABC-treated versus PEN-treated rats (Table 2; $F_{(1,21)}=0.45, P=0.51$ ), but that the incorrect trial latency was significantly longer than the correct trial latency $\left(F_{(1,21)}=13.62, P=0.001\right)$. There was no significant interaction between treatment and latency type $\left(F_{(1,21)}=1.49, P=0.24\right)$. 
Table 2. Correct, incorrect, and reward latencies for rats tested in conditions 1,2 , and 3 of the experiment

\begin{tabular}{|c|c|c|c|}
\hline Condition & Correct latency & Incorrect latency & Reward latency \\
\hline \multicolumn{4}{|l|}{ mPFC } \\
\hline 1 (6 sec delay, $20 \mathrm{sec}$ ITI) & $\begin{array}{l}\text { PEN, } 5.20 \pm 1.7 \\
\text { Ch, } 5.15 \pm 2.3 \\
\text { ME, Corr }<\text { Incorr }\end{array}$ & $\begin{array}{l}\text { PEN, } 6.01 \pm 1.8 \\
\text { Ch, } 6.72 \pm 3.6\end{array}$ & $\begin{array}{l}\text { PEN, } 1.81 \pm 0.5 \\
\text { Ch,1.71 } \pm 0.4\end{array}$ \\
\hline 2 ( $2 \mathrm{sec}$ and $6 \mathrm{sec}$ delay) & $\begin{array}{l}\text { PEN, } 5.22 \pm 1.9 \\
\text { Ch, } 5.83 \pm 2.6 \\
\text { ME, Corr }<\text { Incorr }\end{array}$ & $\begin{array}{l}\text { PEN, } 6.28 \pm 2.4 \\
\text { Ch, } 7.78 \pm 4.4\end{array}$ & $\begin{array}{l}\text { PEN, } 1.60 \pm 0.4 \\
\text { Ch, } 1.65 \pm 0.5\end{array}$ \\
\hline 3 ( 2 sec delay, $1 \mathrm{sec}$ ITI) & $\begin{array}{l}\text { PEN, } 6.04 \pm 2.0 \\
\text { Ch, } 6.42 \pm 2.8 \\
\text { ME, Corr }<\text { Incorr }\end{array}$ & $\begin{array}{l}\text { PEN, } 7.03 \pm 2.3 \\
\text { Ch, } 8.38 \pm 5.0\end{array}$ & $\begin{array}{l}\text { PEN, } 1.58 \pm 0.4 \\
\text { Ch, } 1.67 \pm 0.5\end{array}$ \\
\hline \multicolumn{4}{|c|}{ - } \\
\hline 1 (6 sec delay, $20 \mathrm{sec}$ ITI) & $\begin{array}{l}\text { PEN, } 5.61 \pm 2.8 \\
\text { Ch, } 6.97 \pm 3.6\end{array}$ & $\begin{array}{l}\text { PEN, } 6.60 \pm 3.6 \\
C h, 7.53 \pm 4.0\end{array}$ & $\begin{array}{l}\text { PEN, } 1.69 \pm 0.4 \\
\text { Ch, } 2.10 \pm 0.7\end{array}$ \\
\hline 2 ( $2 \mathrm{sec}$ and $6 \mathrm{sec}$ delay) & $\begin{array}{l}\text { PEN, } 5.66 \pm 2.6 \\
\text { Ch, } 6.28 \pm 2.5 \\
\text { ME, Corr }<\text { Incorr }\end{array}$ & $\begin{array}{l}\text { PEN, } 6.44 \pm 2.8 \\
\text { Ch, } 7.65 \pm 3.7\end{array}$ & $\begin{array}{l}\text { PEN, } 1.69 \pm 0.4 \\
\text { Ch, } 2.28 \pm 0.4\end{array}$ \\
\hline 3 ( 2 sec delay, $1 \mathrm{sec}$ ITI) & $\begin{array}{l}\text { PEN, } 6.52 \pm 3.3 \\
\text { Ch, } 6.99 \pm 3.3 \\
\text { ME, Corr }<\text { Incorr }\end{array}$ & $\begin{array}{l}\text { PEN, } 8.28 \pm 4.7 \\
\text { Ch, } 8.77 \pm 3.6\end{array}$ & $\begin{array}{l}\text { PEN, } 1.77 \pm 0.5 \\
\text { Ch, } 2.19 \pm 0.8\end{array}$ \\
\hline
\end{tabular}

Group means \pm SEM are show for ChABC (Ch) or PEN infused rats. The mPFC group is shown on the top and the PPC group on the bottom. ME refers to a main effect of Latency in the ANOVA. See Results for details.

\section{ChABC infusions in the mPFC improved performance of rats in condition 4 on the first two testing days (20 sec delay)}

Overall percent accuracy was not significantly different between PEN and ChABC-treated rats (Fig. $\left.3 \mathrm{~A} ; F_{(1,21)}=3.00, P=0.10\right)$. Additionally, there was no main effect of testing day $\left(F_{(2,42)}=\right.$ 2.66, $P=0.08)$, and no interaction between treatment and testing day $\left(F_{(2,42)}=1.19, P=0.32\right)$. The percent accuracy for trials with large separations was not significantly different between PEN and ChABC-treated rats (Fig. 3B; $F_{(1,21)}=1.60, P=0.22$ ). Furthermore, there was no main effect of testing day $\left(F_{(2,42)}=1.60, P=0.21\right)$ and no interaction between treatment and testing day $\left(F_{(2,42)}=\right.$ 2.30, $P=0.11)$. The percent accuracy for trials with small separations was not significantly different between PEN and ChABC-treated rats (Fig. 3C; $F_{(1,21)}=2.14, P=0.16$ ). There was also was no main effect of testing day $\left(F_{(2,42)}=1.13, P=0.33\right)$, and no interaction between treatment and testing day $\left(F_{(2,42)}=\right.$ $0.42, P=0.66$ ).

There was no significant difference in the number of total trials completed by PEN and ChABC-treated rats (Fig. 3D; $F_{(1,21)}=$ 2.93, $P=0.10)$. In addition, there was no main effect of testing day $\left(F_{(2,42)}=0.69, P=0.51\right)$, and no interaction between treatment and testing day $\left(F_{(2,42)}=2.15, P=0.13\right)$. There was also no significant difference in the number of selection trials completed by PEN and ChABC-treated rats (Fig. 3E; $F_{(1,21)}=0.42, P=0.53$ ). However, there was a significant main effect of testing day $\left(F_{(2,42)}\right.$ $=9.95, P<0.001)$, and a significant interaction between treatment and testing day $\left(F_{(2,42)}=4.37, P=0.019\right)$. Post hoc analyses (Tukey's) revealed that rats performed significantly more selection trials on testing days 12-13 compared to testing days 10-11 $(P<$ $0.05)$, as well as significantly more selection trials on testing days 14-15 compared to testing day 10-11 $(P<0.05)$. There was no difference in the number of correction trials completed by PEN and ChABC-treated rats (Fig. 3F; $F_{(1,21)}=3.60, P=0.07$ ). There was, however, a significant main effect of testing day $\left(F_{(2,42)}=15.53, P<\right.$ $0.001)$, but no interaction between treatment and testing day $\left(F_{(2,42)}=2.69, P=0.079\right)$. Post hoc analyses revealed that rats performed fewer correction trials on testing days $12-13(P<0.05)$ and $14-15(P<0.05)$ compared to testing days $10-11$.

An independent-samples $t$-test revealed that PEN and ChABC-treated rats did not have any significant differences in reward latency (Fig. 3G; $t_{(21)}=-0.30, P=0.77$ ). A $2 \times 2$ ANOVA re- vealed no significant difference in the correct and incorrect trial latency of ChABC-treated versus PEN-treated rats (Fig. $3 \mathrm{H}$; $\left.F_{(1,21)}=0.82, P=0.38\right)$, but the incorrect trial latency was significantly longer than the correct trial latency $\left(F_{(1,21)}=9.34, P=\right.$ 0.006). There was no interaction between treatment and latency type $\left(F_{(1,21)}=2.59, P=0.12\right)$.

When investigating the initial $2 \mathrm{~d}$ of the $20 \mathrm{sec}$ delay condition (testing days 10-11), independent samples t-tests revealed that ChABC-treated rats initially had a higher total percent accuracy (Fig. $\left.3 \mathrm{~A} ; t_{(21)}=-3.38, P=0.003\right)$, higher large separation percent accuracy (Fig. 3B; $t_{(21)}=-2.74, P=0.012$ ), more selection trials completed (Fig. 3E; $t_{(21)}=-2.31, P=0.031$ ), and fewer correction trials completed (Fig. 3F; $t_{(21)}=3.52, P=0.002$ ) compared to PEN-treated rats. There were no significant differences in small separation percent accuracy (Fig. $3 \mathrm{C} ; t_{(21)}=-1.528, P=0.14$ ), total trials completed (Fig. 3D; $t_{(21)}=0.92, P=0.37$ ) between ChABC-treated rats and PEN-treated rats over the first $2 \mathrm{~d}$ of the 20 sec delay.

\section{ChABC infusions into the PPC do not alter performance of rats in the TUNL task}

\section{ChABC infusions in the PPC had no effect on the performance of rats in condition 1 (6 sec delay)}

A $2 \times 2$ ANOVA (treatment, separation) revealed that the accuracy of PEN and ChABC-treated rats was not significantly different (Table 1; $F_{(1,22)}=3.48, P=0.08$ ). Rats performed better on trials with large separations compared to trials with small separations $\left(F_{(1,22)}=18.34, P<0.001\right)$, and there was no interaction between separation and treatment $\left(F_{(1,22)}=0.25, P=0.62\right)$. Independentsamples $t$-tests revealed that $\mathrm{ChABC}$-treated rats did not perform significantly differently from PEN-treated rats in terms of total trials completed (Table $1 ; t_{(22)}=0.93, P=0.36$ ), selection trials completed (Table $1 ; t_{(22)}=1.29, P=0.21$ ), correction trials completed (Table $\left.1 ; t_{(22)}=-0.12, P=0.91\right)$, or reward latency (Table $2 ; \mathrm{t}(22)=$ $-1.76, P=0.09$ ). In addition, a $2 \times 2$ ANOVA revealed that there was no difference in the correct and incorrect trial latency of ChABC-treated versus PEN-treated rats (Table 2; $F_{(1,22)}=0.73, P=$ $0.40)$, and that the there was no difference in correct and incorrect trial latencies $\left(F_{(1,22)}=2.50, P=0.13\right)$. There was no significant 
A

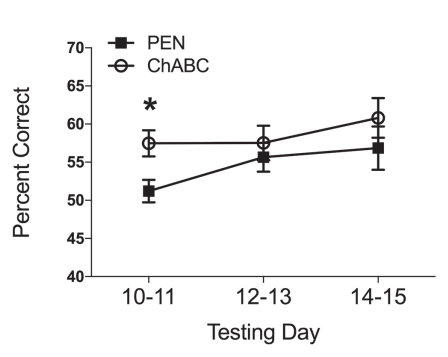

C

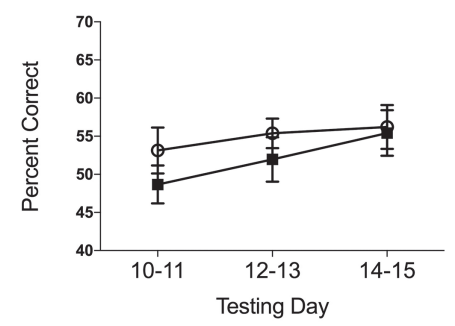

E

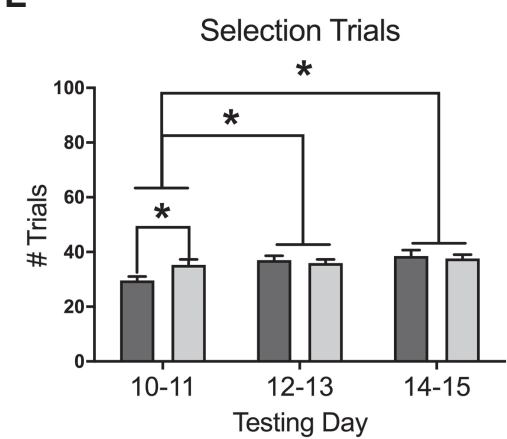

G

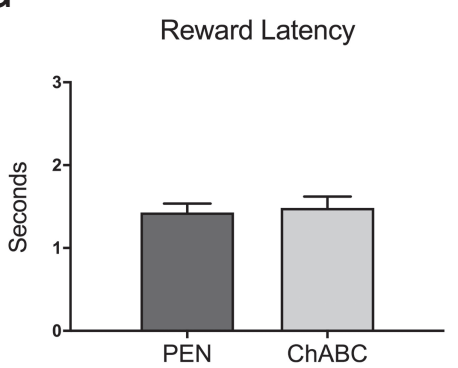

B

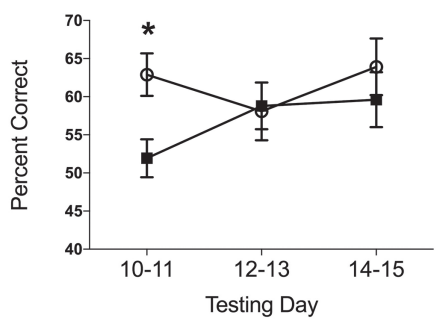

D

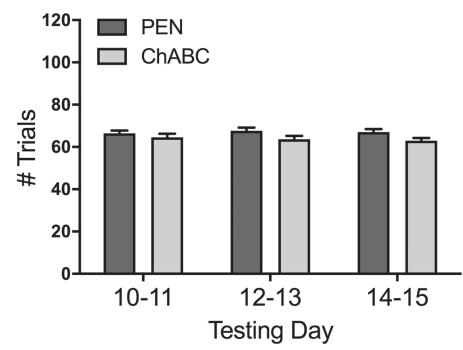

F

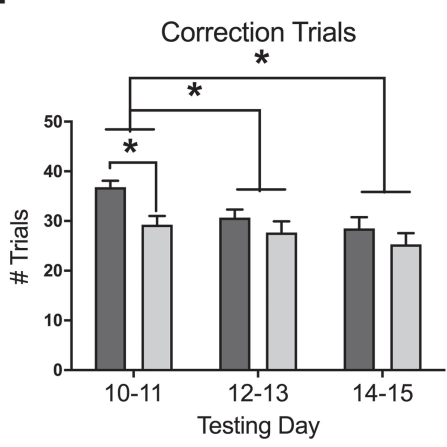

H

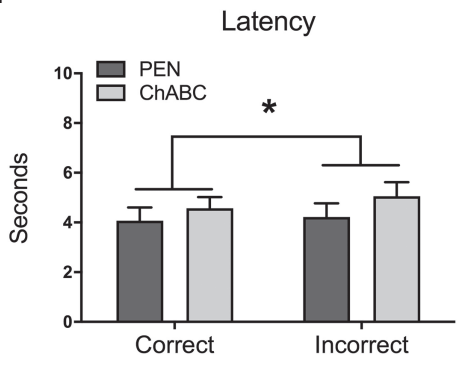

Figure 3. Effects of PEN or ChABC infusions into the mPFC on TUNL with a 20 sec delay period (Condition 4). All values represent the mean \pm SEM of the testing days. ( $A$ ) ChABC-treated rats had a significantly higher overall percent accuracy than PEN-treated rats over the first $2 \mathrm{~d}$ of testing, but not over the full $6 \mathrm{~d}$ of testing. (B) ChABC-treated rats had a significantly higher percent accuracy on trials with large stimulus separations compared to PEN-treated rats over the first $2 \mathrm{~d}$ of testing, but not over the full $6 \mathrm{~d}$ of testing. ChABC had no effect on percent accuracy in trials with small stimulus separations (C) or the number of total trials completed $(D)$. $(E)$ ChABC-treated rats completed significantly more selection trials than PEN-treated rats over the first $2 \mathrm{~d}$ of testing, but not over the full $6 \mathrm{~d}$ of testing. Rats performed significantly more selection trials on testing days 12-13 and 14-15 compared to testing days 10-11. (F) ChABC-treated rats completed significantly fewer correction trials than PEN-treated rats over the first $2 \mathrm{~d}$ of testing, but not over the full $6 \mathrm{~d}$ of testing. Rats performed significantly fewer correction trials on testing days 12-13 and 14-15 compared to testing days 10-11. ChABC had no effect on reward latency $(G)$, correct latency $(H)$, or incorrect latency $(H)$. Incorrect choice latency was significantly longer than correct choice latency $(H)$. PEN, $n=12$; ChABC, $n=11$. Note that accuracy of $50 \%$ is chance performance in the TUNL task. $\left(^{*}\right) P<0.05$. Note that accuracy of $50 \%$ is chance performance in the TUNL task. interaction between treatment and latency type $\left(F_{(1,22)}=0.20, P=0.66\right)$.

\section{ChABC infusions in the PPC had no effect on the performance of rats in condition 2 (variable 2 or 6 sec delay)}

A three-way ANOVA (treatment, separation, delay) revealed no significant differences between ChABC and PEN-treated rats (Table $1 ; F_{(1,22)}=0.00, \quad P=0.96$ ). There was also no significant main effect of separation $\left(F_{(1,22)}=2.23, P=0.14\right)$, but there was a significant main effect of delay $\left(F_{(1,22)}=145.69, P<0.001\right)$ as well as an interaction between the two was observed $\left(F_{(1,22)}=46.66, \quad P<0.001\right)$. Post hoc analyses revealed that the percent accuracy on trials with a 2 sec delay and large separations was significantly higher than other trial types $(P<0.05)$. In addition, the percent accuracy on trials with a 2 sec delay and small separations was also significantly higher than trials with a 6 sec delay and large separations $(P<$ $0.05)$ but not trials with a 6 sec delay and small separations $(P>0.05)$. Percent accuracy on trials with a 6 sec delay and a small separations was also significantly higher than that on trials with a 6 sec delay and large separations $(P<0.05)$. There were no significant interactions between treatment and delay (Table $1 ; F_{(1,22)}=$ $0.03, P=0.86)$, treatment and separation $\left(F_{(1,22)}=0.00, P=0.99\right)$, or treatment $\times$ delay $\times$ separation $\left(F_{(1,22)}=0.02, P=0.89\right)$.

Independent-samples $t$-tests revealed that $\mathrm{ChABC}$-treated rats did not perform significantly differently from PEN-treated rats in terms of total trials completed (Table $1 ; t_{(22)}=1.11, P=0.28$ ), selection trials completed (Table $1 ; t_{(22)}=$ $0.79, P=0.44)$, correction trials completed (Table $1 ; t_{(22)}=0.90, P=0.38$ ), or reward latency (Table 2; $t(22)=-1.91, P=$ 0.07). A $2 \times 2$ ANOVA revealed no significant difference in the correct and incorrect trial latency of ChABC-treated versus PEN-treated rats (Table 2; $F_{(1,22)}=$ $0.65, P=0.43)$, but the incorrect trial latency was significantly longer than the correct trial latency $\left(F_{(1,22)}=6.23, P=\right.$ $0.02)$. There was no significant interaction between treatment and latency type $\left(F_{(1,22)}=0.48, P=0.49\right)$.

\section{ChABC infusions in the PPC had no effect on the} performance of rats in condition 3 (2 sec delay with a 1 sec ITI)

A $2 \times 2$ ANOVA revealed that the percent accuracy of ChABC-treated rats was not significantly different than that of PEN-treated rats (Table $1 ; F_{(1,22)}=0.20$, $P=0.66$ ). However, the rats performed significantly better on large separation 
trials compared to small separation trials $\left(F_{(1,22)}=25.36, P<0.001\right)$, but there was no significant interaction between separation and treatment $\left(F_{(1,22)}=0.16, P=\right.$ $0.70)$. Independent-samples $t$-tests revealed that ChABC-treated rats did not perform significantly differently from PEN-treated rats in terms of total trials (Table $1 ; t_{(22)}=1.75, P=0.09$ ), selection trials (Table $1 ; t_{(22)}=1.49, \quad P=0.15$ ), correction trials (Table $1 ; t_{(22)}=0.70, P=$ 0.49 ), or reward latency (Table $2 ; t_{(22)}=$ $-1.58, P=0.13)$. A $2 \times 2$ ANOVA revealed no significant difference in the correct and incorrect trial latency of ChABC-treated versus PEN-treated rats (Table 2; $\left.F_{(1,22)}=0.11, P=0.75\right)$, but that the incorrect trial latency was significantly longer than the correct trial latency $\left(F_{(1,22)}=21.88, P<0.001\right)$. There was no significant interaction between treatment and latency type $\left(F_{(1,22)}=0.00, P=\right.$ 0.99).

ChABC infusions in the PPC had no effect on the performance of rats in condition 4 (20 sec delay) Overall accuracy was not significantly different between PEN and ChABC-treated rats (Fig. $4 \mathrm{~A} ; F_{(1,22)}=0.25, P=0.62$ ). In addition, there was no main effect of testing day $\left(F_{(2,44)}=0.59, P=0.56\right)$ or interaction between treatment and testing day $\left(F_{(2,44)}=0.20, P=0.82\right)$. The percent accuracy for trials with large separations was not significantly different between PEN and ChABC-treated rats (Fig. 4B; $F_{(1,22)}=$ 2.92, $P=0.10)$. Furthermore, there was no main effect of testing day $\left(F_{(2,44)}=\right.$ $0.64, P=0.54)$ and no interaction between treatment and testing day $\left(F_{(2,44)}=0.94, P\right.$ $=0.40)$. The percent accuracy for trials with small separations was not significantly different between PEN and ChABC-treated rats (Fig. $4 \mathrm{C} ; F_{(1,22)}=0.93$, $P=0.35)$. There was also was no main effect of testing day $\left(F_{(2,44)}=0.35, P=0.71\right)$, and no interaction between treatment and testing day $\left(F_{(2,44)}=0.28, P=0.76\right)$.

There was no difference in the number of total trials completed by PEN and ChABC-treated rats (Fig. $4 \mathrm{D} ; F_{(1,22)}=$ $0.97, P=0.34)$. However, there was a main effect of testing day $\left(F_{(2,44)}=4.19\right.$, $P=0.022)$, but no interaction between treatment and testing day $\left(F_{(2,44)}=0.98\right.$, $P=0.39$ ). Post hoc analyses revealed that rats performed significantly more total trials on days 5-6 compared to days 1-2 $(P<0.05)$. There was also no difference in the number of selection trials completed by PEN and ChABC-treated rats (Fig. $4 \mathrm{E} ; F_{(1,22)}=0.06, P=0.81$ ). There was a significant main effect of testing day $\left(F_{(2,44)}=9.21, P<\right.$ $0.001)$, but no interaction between treatment and testing day $\left(F_{(2,44)}=0.62, P=0.55\right)$. Post hoc analyses revealed that rats performed significantly more selection trials on days 5-6 compared performance in the TUNL task.
A

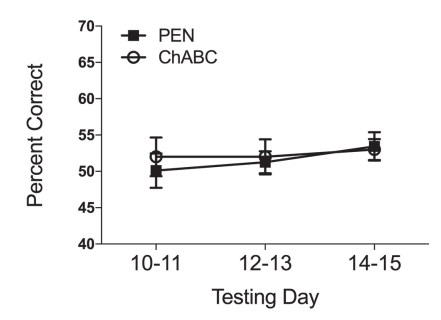

C

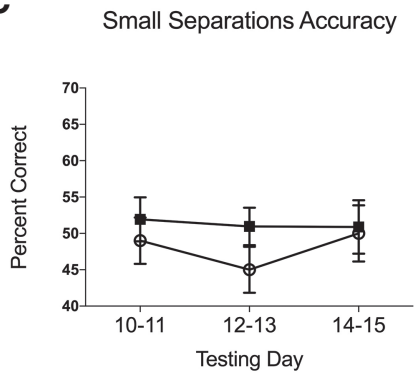

E

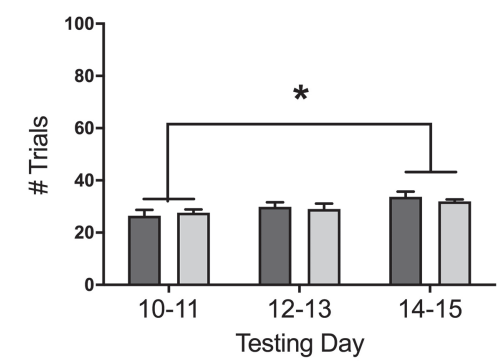

G

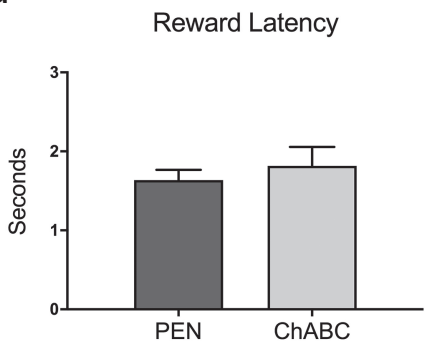

B

Large Separations Accuracy

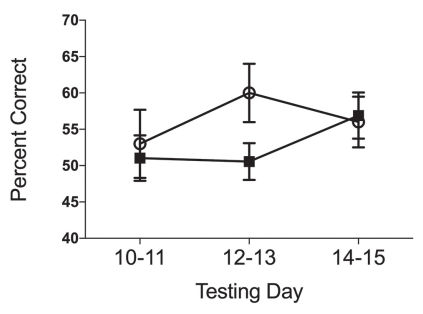

D

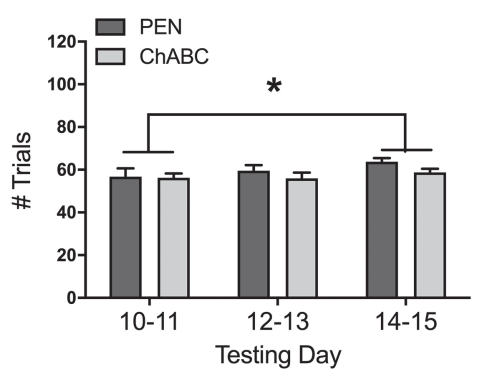

$\mathbf{F}$

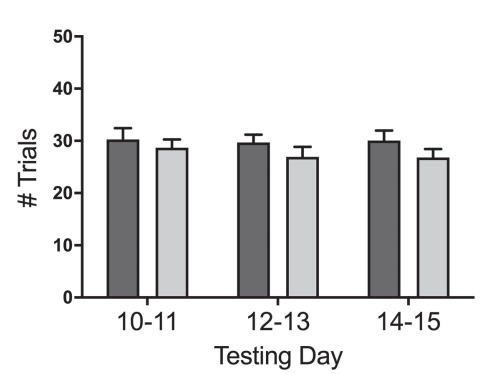

H

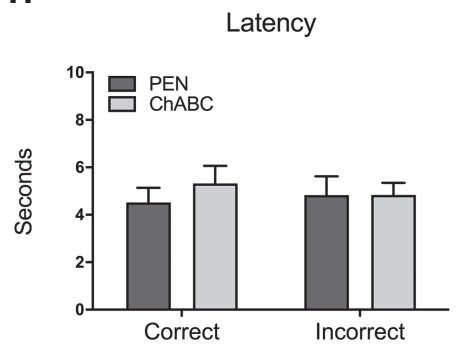

Figure 4. Effects of PEN or ChABC infusions into the PPC on TUNL with a delay of $20 \mathrm{sec}$ (Condition 4). All values represent the mean $\pm S E M$ of the testing days. $C h A B C$ had no effect on overall percent accuracy $(A)$, the percent accuracy on trials with large stimulus separations $(B)$, the percent accuracy on trials with small stimulus separations $(C)$, the total number of trials completed $(D)$, the number of selection trials completed $(E)$, the number of correction trials completed $(F)$, reward latency $(G)$, or correct or incorrect latencies $(H)$. Rats performed significantly more total trials on testing days 14-15 compared to testing days $10-11(D)$. Rats performed significantly more selection trials on testing days $14-15$ compared to testing days $10-11(E)$. PEN, $n=12$; ChABC, $n=12 .\left(^{*}\right) P<0.05$. Note that accuracy of $50 \%$ is chance

to days $1-2(P<0.05)$. There was no difference in the number of correction trials completed by PEN and ChABC-treated rats (Fig. $\left.4 \mathrm{~F} ; F_{(1,22)}=1.52, P=0.23\right)$. There was also no significant main effect of testing day $\left(F_{(2,44)}=0.46, P=0.63\right)$ and no interaction between treatment and testing day $\left(F_{(2,44)}=0.22, P=0.81\right)$. 
An independent samples $t$-test revealed that PEN and ChABC-treated rats had no significant differences in reward latency (Fig. $4 \mathrm{G} ; t_{(22)}=-1.43, P=0.17$ ). A $2 \times 2$ ANOVA revealed no significant difference in the correct and incorrect trial latency of ChABC-treated versus PEN-treated rats (Fig. $4 \mathrm{H} ; F_{(1,22)}=0.19$, $P=0.66)$, There was also no difference between correct trial latency and incorrect trial latency $\left(F_{(1,22)}=0.14, \quad P=0.72\right)$, as well as no interaction between treatment and latency type $\left(F_{(1,22)}=2.67, P=0.12\right)$.

When investigating the initial $2 \mathrm{~d}$ of the 20 sec delay condition (testing days 10-11), independent samples $t$-tests revealed no significant differences between PEN and ChABC-treated rats on total percent accuracy (Fig. 4A; $t_{(22)}=-0.39, P=$ $0.70)$, large separation percent accuracy (Fig. $\left.4 \mathrm{~B} ; t_{(22)}=-0.49, P=0.63\right)$, small separation percent accuracy (Fig. $4 \mathrm{C} ; t_{(22)}=$ $0.50, P=0.62)$, total trials completed (Fig. $\left.4 \mathrm{D} ; t_{(22)}=0.09, P=0.93\right)$, selection trials completed (Fig. $4 \mathrm{E} ; t_{(22)}=-0.46, P=$ $0.65)$, or correction trials completed (Fig. $\left.4 \mathrm{~F} ; t_{(22)}=0.58, P=0.57\right)$.

\section{Quantification of the effects of $\mathrm{ChABC}$ on PNNs in the mPFC and PPC}

To confirm the degradation of CSPGs and PNNs by ChABC in the mPFC, we stained with Wisteria Floribunda Agglutinin (WFA), a marker for CSPGs that preferentially labels PNNs, and mouse anti-chondroitin-4-sulfate (C4S), a marker for cleaved components of CSPGs (Fig. 5). WFA intensity was significantly reduced within the mPFC of ChABC-treated rats compared to controls (Fig. 5D; $\left.t_{(20)}=3.78, P=0.001\right)$. Staining intensity for C4S was significantly higher within the mPFC of ChABC-treated rats than in controls (Fig. $\left.5 \mathrm{E} ; t_{(20)}=-3.81, P=0.001\right)$. As a control reference region, the somatosensory jaw area (S1J) was assessed. In this region, there was no difference in WFA (Fig. $5 \mathrm{D} ; t_{(20)}=1.89, P=0.07$ ) or C4S (Fig. 5E; $\left.t_{(20)}=-0.79, P=0.44\right)$ intensities compared to controls. This data is consistent with previous findings that PNNs are still reduced and C4S stubs still significantly elevated within the treatment area $30 \mathrm{~d}$ after injection (Paylor et al. 2018).

PNNs commonly ensheathe parvalbumin containing (PV+) inhibitory interneurons in the cortex (Härtig et al. 1992). To assess whether degradation of PNNs was paired with PV+ interneuron loss, staining with an antibody specific to $\mathrm{PV}+$ was performed (Fig. 6). PNN counts (Fig. 6E; $t_{(21)}=3.129, P=0.005$ ), PV+ cell counts (Fig. 6F; $t_{(21)}=2.39, P=0.027$ ), and the percentage of $\mathrm{PV}+$ cells surrounded by PNNs (Fig. 6G; $t_{(21)}=2.23, P=0.037$ ) were all significantly reduced in ChABC-treated rats compared to controls.

Staining intensity for C4S was significantly higher within the PPC of ChABC-treated rats than in controls (Fig. 7D; $t_{(22)}=$ $-2.46, P=0.022)$. WFA intensity, however, was not significantly different within the PPC of ChABC-treated rats compared to controls (Fig. 7E; $t_{(22)}=0.83, P=0.42$ ). As a control reference region, an area lateral to the PPC was chosen. In this region, there was no difference in WFA (Fig. 7D; $t_{(22)}=0.43, P=0.68$ ) or C4S (Fig. $7 \mathrm{E} ; t_{(22)}=0.35, P=0.73$ ) intensities compared to controls.

Like the protocol for the $\mathrm{mPFC}$, the number of PV+ cells and PNNs was also assessed in the PPC (Fig. 8). ChABC-treated rats were not significantly different than controls in terms of PNN count
(Fig. 8E; $\left.t_{(21)}=0.424, P=0.676\right), P V+$ cell count $\left(\right.$ Fig. $8 \mathrm{~F} ; t_{(21)}=$ $-0.08, P=0.94)$, or the percentage of $\mathrm{PV}+$ cells surrounded by PNNs (Fig. $8 \mathrm{G} ; t_{(21)}=-0.03, P=0.97$ ).

PNN regrowth in the mPFC following $C h A B C$ treatment WFA intensity was normalized for each rat by using $\mathrm{S} 1$ as a control reference region. PEN-treated rats that were sacrificed $30 \mathrm{~d}$ after surgery had a significantly higher normalized WFA intensity than ChABC-treated rats that were sacrificed $7 \mathrm{~d}$ after surgery (Fig. 9; $\left.t_{(14)}=3.66, P=0.003\right)$ and $30 \mathrm{~d}$ after surgery $\left(t_{(21)}=3.23, P=\right.$ $0.004)$. ChABC-treated rats that were sacrificed $30 \mathrm{~d}$ after surgery had a significantly higher normalized WFA intensity than ChABC-treated rats that were sacrificed $7 \mathrm{~d}$ after surgery $\left(t_{(13)}=\right.$ 4.13, $P=0.001)$.

\section{Discussion}

Targeted delivery of ChABC into the mPFC and PPC was performed to degrade CSPGs and PNNs prior to rats being tested on the TUNL task. ChABC infusions into the mPFC initially led to a higher percent accuracy, more selection trials completed, and fewer correction trials when a novel 20 sec delay (condition 4) was introduced in the TUNL task. ChABC infusions into the mPFC had no effect on a standard 6 sec delay (condition 1), a variable 2 or 6 sec delay (condition 2), or an interference condition (condition 3) in TUNL. ChABC infusions into the PPC resulted in no effect in any of the 4 TUNL conditions. Notably, immunohistochemistry revealed that $\mathrm{ChABC}$ infusions into the MPFC increased C4S intensity and decreased WFA intensity. Furthermore, ChABC significantly reduced PNN count, PV+ cell count, and the percent of PV+ cells surrounded by PNNs. In the PPC, ChABC infusions led to increased C4S intensity, but had no effect on WFA intensity, PNN count, PV+ cell count, or the percent of PV+ cells surrounded by PNNs. 

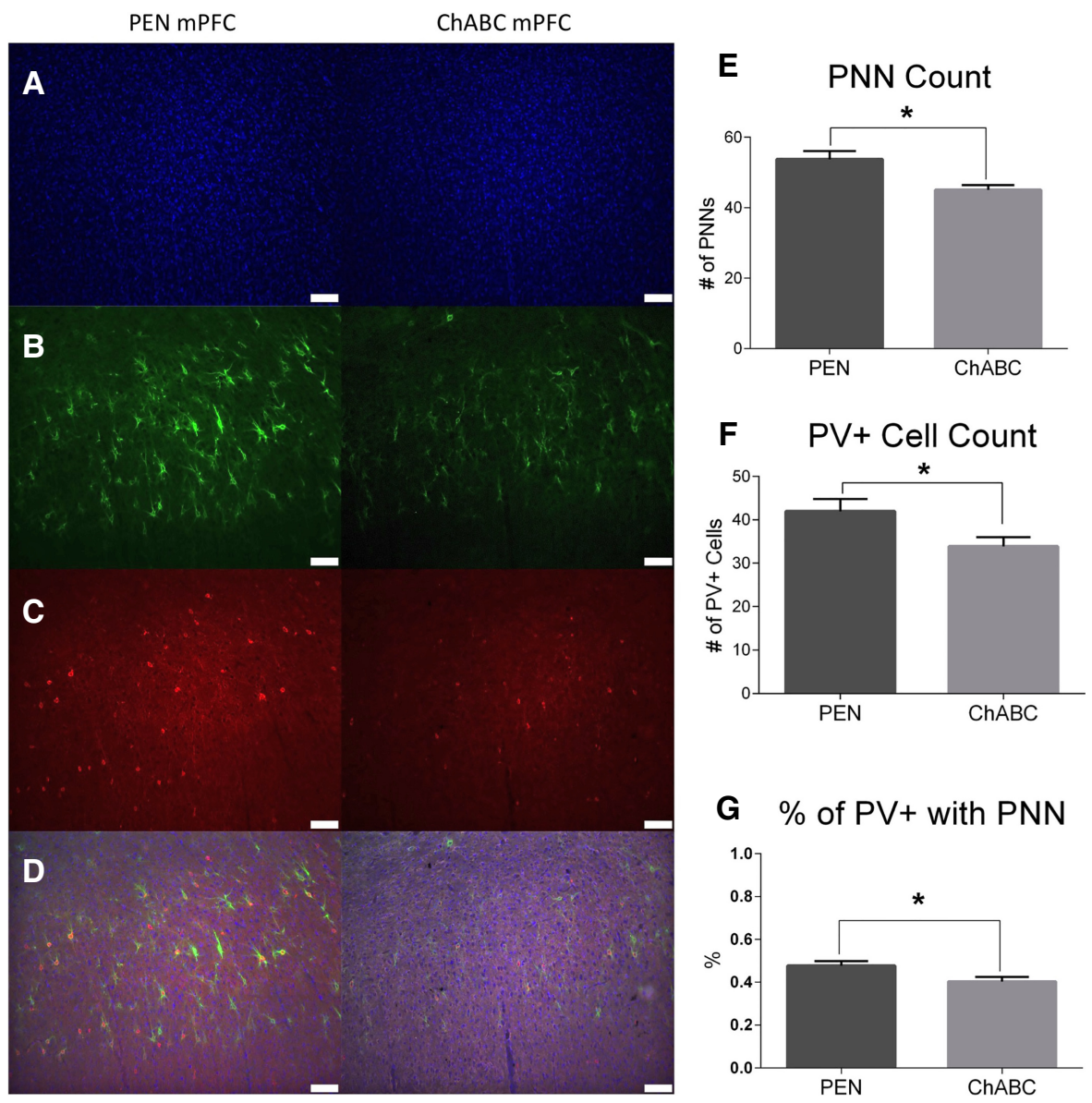

Figure 6. $C h A B C$ infusions into the $m P F C$ reduced $P V+$ cell density but did not affect PNN density Representative images of $(A)$ DAPI, $(B)$ WFA, $(C)$ PV+, and $(D)$ merged images. (E) ChABC had no effect on PNN density $(F)$ The density of PV+ interneurons significantly decreased following ChABC infusions. $(G)$ ChABC-treated animals had significantly fewer PV+ cells surrounded by PNNs compared to controls. PEN, $n=12$; ChABC, $n=11 ;\left(^{*}\right) P<0.05$.

In the present study, stereotaxic coordinates and ChABC volumes for mPFC infusions were based on our previous study (Paylor et al. 2018). Like our previous study, mPFC infusions of ChABC significantly increased C4S intensity, indicative of more CSPG stubs, and decreased WFA intensity, indicative of fewer intact CSPGs in the ECM. The physiological role for the persistence of C4S stubs near the injection site is not entirely clear. While PNNs have been shown to begin to reappear $30 \mathrm{~d}$ after ChABC treatment, our studies suggest that $\mathrm{C} 4 \mathrm{~S}$ staining remains elevated after the same period (Slaker et al. 2015; Paylor et al. 2018). In both the present study and our previous study, PNNs were significantly decreased following ChABC infusions (Paylor et al. 2018). As PNNs were only partially reduced, some sparing of function is likely. There was also a reduction in PV+ cells in the present study; however, PV+ cell counts were unaffected in our previous study. Because PNNs protect the neurons that they ensheathe from oxidative stress and support functional cell signaling and ion buffering (Brückner et al. 1993; Morawski et al. 2004; Dzyubenko et al. 2016), PNN degradation may have impaired the physiological function of PV+ interneurons that they surrounded, which could have led to PV+ cell loss (Morishita et al. 2015; Chu et al. 2018). This mechanism, in part, has been elucidated using 8-oxo-7,8-dihydro-20-deoxyguanine (8-oxo-dG), a marker for DNA oxidation, which has shown that PV+ cells lacking a PNN are preferentially affected by oxidative stress
(Cabungcal et al. 2013). Alternatively, the different behavioral tasks performed in the two studies may have led to differences in the experience dependent plasticity of PV+ cell networks (Donato et al. 2013), which could explain why there was a reduction in PV+ cells in the present study, but not our previous study. In future experiments, the activation of PV+ cells, or other neuron subtypes, in ChABC-exposed rats during TUNL could be assessed using c-fos immunohistochemistry in an attempt to address this hypothesis (Paylor et al. 2018).

In contrast to the $\mathrm{mPFC}, \mathrm{ChABC}$ infusions into the PPC had no effect on PNN intensity. The reduction in $\mathrm{mPFC}$ PNNs but not PPC PNNs could have resulted from more ChABC spread in the PPC, since it is wider than the mPFC. The lack of PNN reduction in the PPC may also have resulted from infusions being done anterior to the part of the PPC that was imaged. Infusions were performed between -3.30 and $-3.80 \mathrm{~mm}$ posterior to bregma, while the PPC was imaged between -3.84 and $-4.68 \mathrm{~mm}$ posterior to bregma. Alternatively, PNNs in the PPC may regrow at a faster rate than PNNs in the mPFC. For example, it appears that PNNs in $\mathrm{V} 1$ regrow more quickly than PNNs in the mPFC. After being normalized to a reference region, WFA intensity in the V1 went from about 0.05 seven days postsurgery to 0.6 thirty days postsurgery (Lensjø et al. 2017b). In the present study, the mPFC showed a normalized WFA intensity of about 0.4 seven days postsurgery to 0.7 thirty days postsurgery, although some methodological differences between the studies make direct comparisons difficult. Thus, cortical region-dependent PNN regrowth rate may explain why PNNs in the MPFC, but not the PPC, were significantly reduced in the present study.

The battery of TUNL conditions in this study was designed to assess the effects of PNN degradation on spatial WM, susceptibility to interference, and behavioral flexibility. In general, rats performed better on trials with large separations compared to trials with small separations and on trials with shorter delays compared to trials with longer delays. Interestingly, in a single 60-min block of TUNL with a variable 2 or 6 sec delay (condition 2), rats performed worst on trials with a 6 sec delay and large stimulus separations (Table 1). In contrast, in previous experiments that used consistent 2 and $6 \mathrm{sec}$ delays in counterbalanced 30-min blocks, rats performed worst on trials with a 6 sec delay and small separations, as would be expected based on the difficulty of the discrimination and longer delay (Talpos et al. 2010; Davies et al. 2017; Hurtubise et al. 2017; Scott et al. 2019). The response latency of rats on incorrect trials was longer than the response latency on correct trials, which suggests that rats hesitate when unsure of the correct choice.

The results from the present study support the idea that cortical PNNs play a subtle role in complex cognitive tasks. Rats treated with mPFC ChABC had initially improved accuracy, performed more selection trials, and performed fewer correction trials 


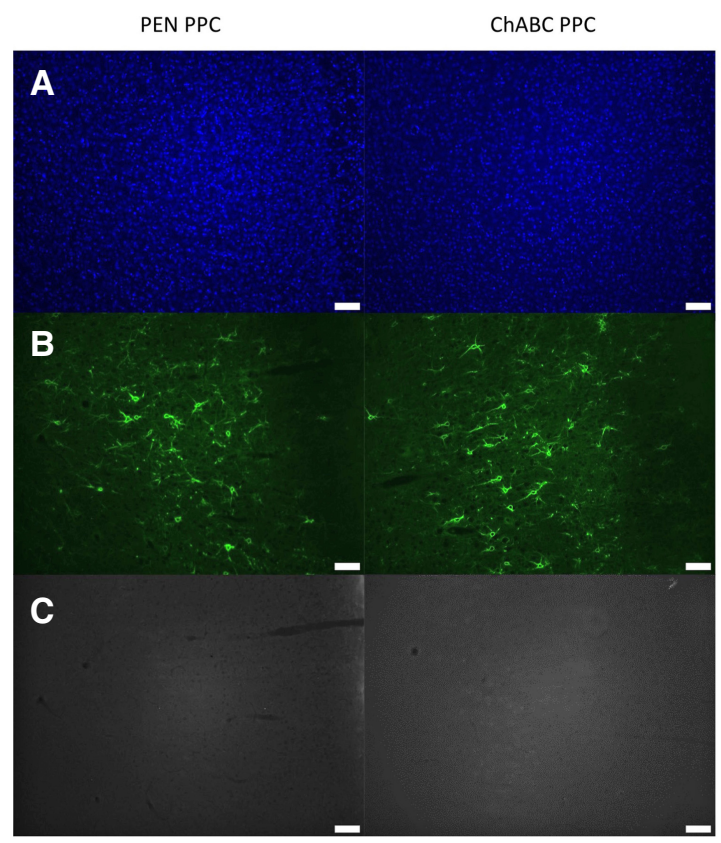

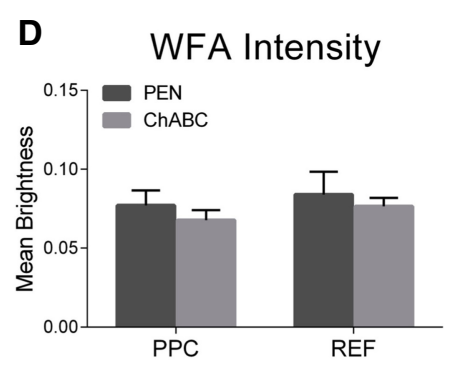

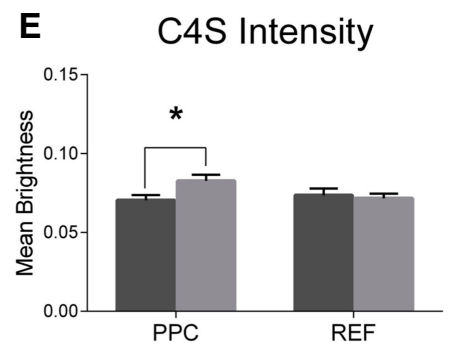

Figure 7. ChABC infusions into the PPC increased C4S staining for cleaved CSPG stubs but had no effect on WFA intensity. Representative images of $(A)$ DAPI, $(B)$ WFA, and $(C) C 4 S$. (D) ChABC infusions into the PPC had no effect on WFA intensity in the PPC or in a reference region lateral to the PPC. $(E)$ ChABC infusions into the PPC significantly increased the intensity of C4S staining in the PPC, but had no effect within a reference region lateral to the PPC. PEN, $n=12 ;$ ChABC, $n=11 ;\left({ }^{*}\right) P<0.05$. ger response latencies in ChABC-treated rats compared to controls in all conditions tested. Finally, improved performance following mPFC ChABC, but not PPC ChABC infusions was surprising, because WM has been proposed to rely on fronto-parietal circuits (Eriksson et al. 2015). Perhaps this dissociation is the result of the mPFC and PPC contributing to spatial WM in different ways.

Performance of the TUNL task depends on a distributed neural circuitry also including the hippocampus (Talpos et al. 2010; Josey and Brigman 2015; Kim et al. 2015). PNNs are expressed in the rodent hippocampus (Seeger et al. 1994; Yamada and Jinno 2013; Lensjø et al. 2017a; Griffiths et al. 2019), in particular in the CA2 subregion (Carstens et al. 2016; Hayani et al. 2018; Domínguez et al. 2019). As PNN degradation in dorsal hippocampus alters behavior and cognition in a number of tasks (Hylin et al. 2013; Domínguez et al. 2019), future studies assessing the effects of disturbing PNNs in dorsal hippocampus on TUNL may contribute to our understanding of their role in the hippocampus.

In conclusion, this experiment showed that modulation of PNNs in compared to controls in the 20 sec delay condition. The initial improvement in accuracy was specific to large separation trials and did not occur in small separation trials. This is likely because small stimulus separation trials at a 20 sec delay are very challenging and difficult for a rat to perform above chance. The performance of more selection trials can be generally attributed to more correct choices being made and lower response latencies. The performance of fewer correction trials represents less perseveration on incorrect choices and can be inferred as increased behavioral flexibility (Kumar et al. 2015; Lins et al. 2015; Hurtubise et al. 2017). This initial improvement when a 20 sec delay was used, but not when 2 or 6 sec delays were used, is a delay-dependent effect, which has previously been observed following mPFC manipulation (Herremans et al. 1996; Delatour and Gisquet-Verrier 1999; McAllister et al. 2013). Perhaps the improved performance of ChABC-treated rats was related to a period of increased synaptic plasticity caused by $\mathrm{ChABC}$, which could have facilitated the functional connections of neurons that are involved in WM. Memory improvements coupled with increased synaptic plasticity have previously been observed in animals with attenuated PNNs (Carulli et al. 2010; Morellini et al. 2010; Romberg et al. 2013). Alternatively, the improvement in initial performance could be the result of increased behavioral flexibility, because the $20 \mathrm{sec}$ delay condition was the only condition that introduced a novel delay. Interestingly, one group observed a similar effect following mPFC lesions. When rats were trained on a 5 sec delay, mPFC lesions impaired performance when they were tested on a novel $20 \mathrm{sec}$ delay (Delatour and Gisquet-Verrier 1999). However, mPFC-lesioned rats that were trained on a variable $0,5,10$, or 20 sec delay were not impaired when switched to a nonvariable 20 sec delay (Gisquet-Verrier et al. 2000). The initial improved performance in the $20 \mathrm{sec}$ delay condition could also be explained by the inability of rats to wait for a stimulus, as this has previously been observed following mPFC inactivation (Narayanan et al. 2006). Consistent with this, results indicated a general trend toward lon- the mPFC results in subtle consequences for adapting to a novel delay in the TUNL spatial WM task, while PNNs in the PPC do not. Automated touchscreen tasks such as TUNL are useful because they allow for careful control over task difficulty, which can reveal subtle behavioral effects associated with PNN reductions. Since reduced cortical PNNs have been observed in patients with CNS disorders, as well as animal models of those disorders, ChABC infusions are a valuable tool for studying the relationship between PNNs and cognition because they allow for PNNs to be acutely degraded in specific brain areas. However, surgical infusions of $\mathrm{ChABC}$ are labor intensive and relatively short-lasting. Recently, an inducible viral vector has been developed that can efficiently and reversibly degrade PNNs by regulated delivery of ChABC (Burnside et al. 2018). In future studies, this technology or other molecules (Stephenson et al. 2019) could be used to carefully control PNN density during behavioral experiments to study the relationship between PNN density and cognitive function.

\section{Materials and Methods}

\section{Subjects}

Forty-eight Long-Evans rats were trained on the TUNL task in two separate cohorts. All animals were housed in clear, ventilated plastic cages in a temperature-controlled vivarium. Each subject was provided with a plastic tube for enrichment and was maintained on a $12 \mathrm{~h}: 12 \mathrm{~h}$ light-dark cycle. All experimental procedures were conducted during the light phase, and subjects were left undisturbed during the dark phase. Animals were food restricted and were maintained at $85 \%$ of their free-feeding weight. Water was available ad libitum, except during testing. All experiments were approved by the University of Saskatchewan Research Ethics Board and were conducted in accordance with the standards of the Canadian Council on Animal Care. 


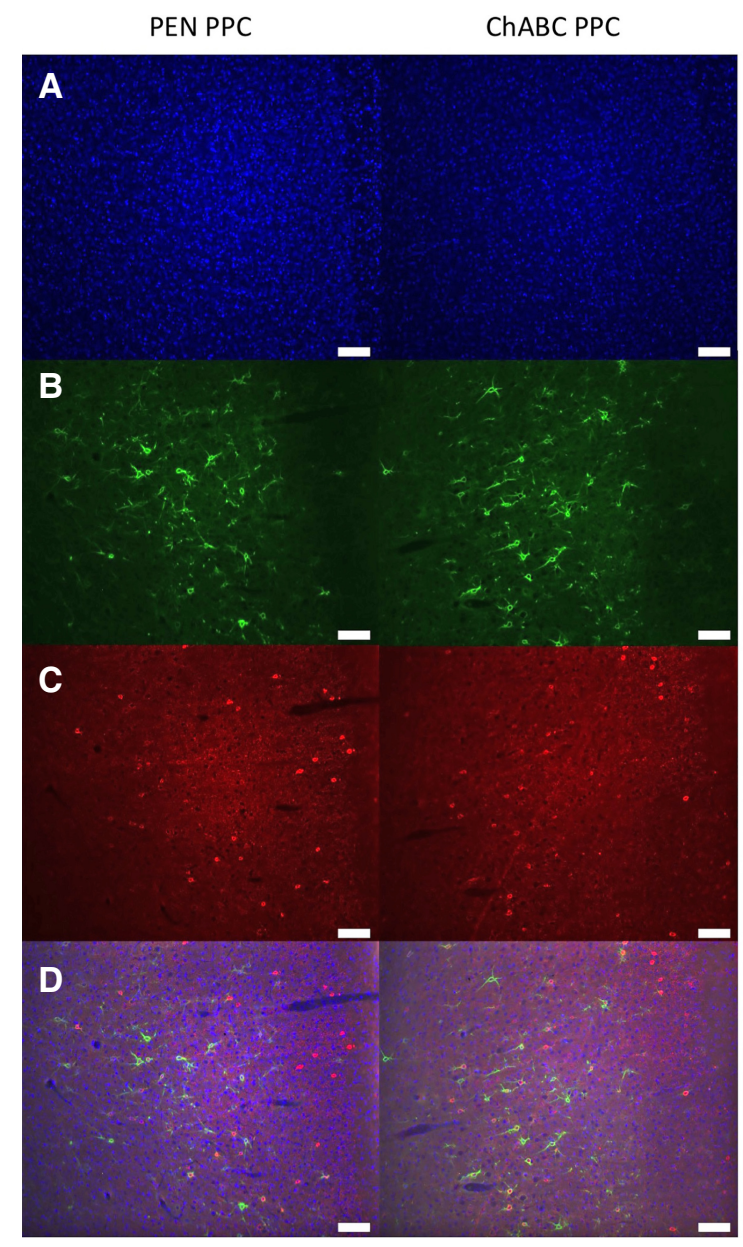

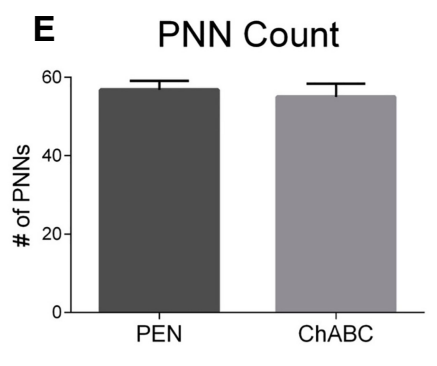

F PV+ Cell Count

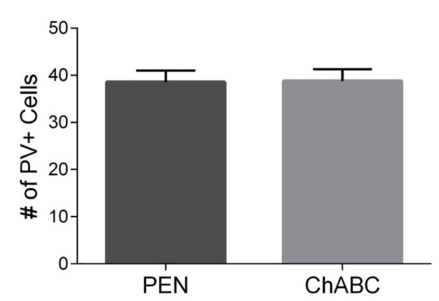

G \% of PV+ with PNN

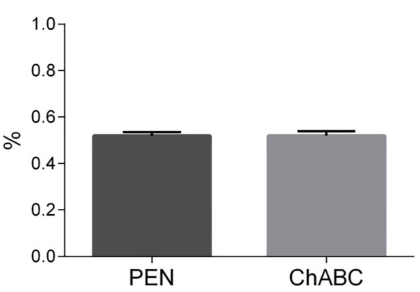

Figure 8. ChABC infusions into the PPC did not reduce $P N N$ density or $P V+$ cell density. Representative images of $(A)$ DAPI, $(B)$ WFA, $(C)$ PV+, and $(D)$ merged images. (E) ChABC infusions into the PPC had no effect on PNN density, $(F)$ ChABC infusions into the PPC had no effect on PV+ cell density, $(G)$ ChABC infusions into the PPC had no effect on the percent of PV+ cells surrounded by PNNs. PEN, $n=12$; ChABC, $n=11$.

\section{Training apparatus}

All training and testing took place in eight touchscreen-equipped operant conditioning chambers (Lafayette Instruments). These chambers are trapezoidal in shape, with a food magazine port positioned parallel and across from the wall with the touchscreen. A black polycarbonate mask with 14 squares presented in a $7 \times 2$ pattern (seven squares horizontally, two squares vertically) covered the touchscreen during the TUNL task. This pattern was visually obstructed with the use of a spring-loaded "response shelf" that rats needed to intentionally press down in order to nose-poke the touchscreen. On the opposite side of the chamber, the food magazine dispensed odorless reward pellets (Dustless Precision Pellets, $45 \mathrm{mg}$, Rodent Purified Diet; BioServ). This food magazine was also equipped with a reward light and an infra-red nose-poke detector. A metal mesh with holes constituted the floor of the chamber, and the roof was a transparent plastic lid. Each operant conditioning chamber was located on a sliding shelf at the base of a sound-attenuating large wooden box. In addition to the chamber, each box contained a pellet dispenser, video camera, small ventilation fan, and a house light that was activated following incorrect responses.

\section{Handling and habituation}

Upon being transported to the vivarium, rats were left undisturbed for a minimum of $2 \mathrm{wk}$. After this time, they were each handled for two consecutive days before training began. Each rat was handled in the touchscreen rooms to familiarize them to that environment. To get to this room from the vivarium, rats were transported up an elevator with the use of a cart. After becoming accustomed to this transportation route and handling for 3 $\mathrm{d}$, rats were habituated to the touchscreen box. On the first day of habituation, each rat was assigned to and placed into a specific touchscreen chamber for $1 \mathrm{~h}$. During this time, ten reward pellets were manually placed into the touchscreen's magazine port, and all technology was turned on (two computers, each controlling four touchscreen devices).

\section{TUNL pretraining (Figure 1)}

The pretraining protocol followed a modified version of the instructions provided by Lafeyette, which involved completion of a series of stages until criterion was reached. TUNL pertaining was composed of four stages: initial touch, must touch, must initiate, and punish incorrect. Initial Touch Training introduced the rats to the touchscreen stimuli and their relationship to a food reward. During each trial, 1 of the 14 squares was illuminated. When a rat touched the illuminated square, three reward pellets were immediately dispensed into the food port. If the illuminated square was left untouched for $30 \mathrm{sec}$, however, the stimulus was removed and only a single pellet was dispensed. Each trial was followed by an ITI period of $20 \mathrm{sec}$. In order to reach criterion for Initial Touch Training, rats must have completed 100 trials in 60 min. During each trial of Must Touch Training, 1 of the 14 squares was illuminated but they remained lit until touched

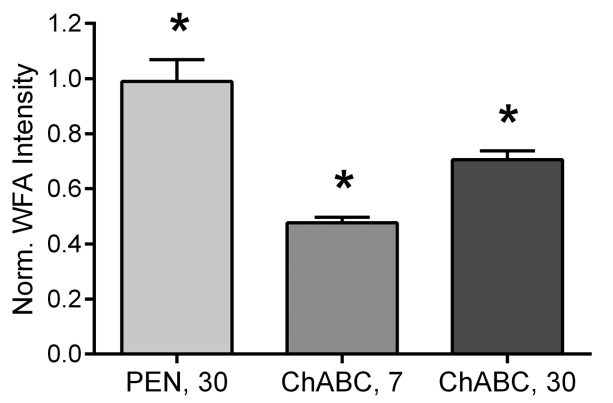

treatment, \# of postsurgery days before sacrifice

Figure 9. Comparison of normalized WFA intensities of rats that were sacrificed $30 \mathrm{~d}$ after mPFC PEN infusions, $7 \mathrm{~d}$ after $\mathrm{mPFC} C$ ChABC infusions, or $30 \mathrm{~d}$ after $\mathrm{mPFC}$ ChABC infusions. WFA intensity was normalized for each rat by using $S 1$ as a control reference region. PEN-treated rats that were sacrificed $30 \mathrm{~d}$ after surgery had a significantly higher normalized WFA intensity than ChABC-treated rats that were sacrificed 7 or $30 \mathrm{~d}$ after surgery. ChABC-treated rats sacrificed $7 \mathrm{~d}$ after surgery had a significantly lower normalized WFA intensity than ChABC-treated rats sacrificed $30 \mathrm{~d}$ after surgery. ChABC 7, $n=4$; $\operatorname{ChABC} 30, n=11$; PEN 30, $n=12$; * significantly different from all other groups $(P<0.05)$. 
by a rat, upon which time a single reward pellet was dispensed. Criterion for this stage involved completing 100 trials in $60 \mathrm{~min}$. During Must Initiate Training, rats are required to poke their nose in the food magazine to initiate trials identical to those in Must Touch Training. Criterion involved completing 100 trials in $60 \mathrm{~min}$. The final pretraining stage was Punish Incorrect Training, in which each trial began with a rat poking its nose into the food reward port. This led to the presentation of a stimulus (illuminated square). If a rat touched the stimulus, a reward pellet was dispensed and a new trial began following an ITI. If the rat touched an unilluminated square, however, a timeout period began. During the timeout, no reward pellet was dispensed, the house light turned on for $5 \mathrm{sec}$, and then an ITI began. The previous trial was then repeated until the rat correctly selected the correct stimulus (these repeated trials were termed as "correction trials"). Criterion was the completion of 100 trials within $60 \mathrm{~min}$ with $>80 \%$ accuracy on two consecutive days.

\section{TUNL task acquisition}

After a rat completed pretraining, it was moved on to learn the standard TUNL task (Fig. 2). Each trial began by a rat poking its nose into the reward magazine. This initiated the sample phase, in which 1 of the 14 squares was lit. If a rat touched one of these illuminated squares, there was a 1 in 3 chance of a pellet being dispensed, and the stimulus was removed from the screen for a 2 sec delay. Following the delay, the rat was required to poke its nose into the reward magazine to start the choice phase. During this phase, the sample square and a novel square were illuminated simultaneously. A correct response was made when the rat touched the novel square (nonmatched to the sample square). Correct responses led to a reward pellet being dispensed, followed by a 20 sec ITI. A new "selection trial" began at the end of the ITI, with a new square being illuminated that had to be different from the previous trial's stimulus. If an incorrect response was made, with the rat selecting the sample square, the house light turned on for $5 \mathrm{sec}$ and no reward was dispensed. After this timeout period, a $20 \mathrm{sec}$ ITI would begin, followed by a trial identical to the previous trial. Trials that repeat the same illuminated sample and choice square stimuli are termed "correction trials," and are repeated consecutively until a correct choice is made. Accuracy was recorded automatically as a measure of the percent of correct responses made during correction trials. During this TUNL acquisition phase, rats were required to complete 42 trials in $30 \mathrm{~min}$. Once the majority ( $>50 \%$ ) of rats reached this criterion, all rats were simultaneously moved onto the final 6-sec delay TUNL task (from the 2 sec TUNL acquisition task). In this final TUNL task, rats were trained until they completed a minimum group average of 50 trials at $65 \%$ accuracy.

\section{PEN and ChABC}

The protocol for preparing PEN and $\mathrm{ChABC}$ was based on previous work (Romberg et al. 2013; Paylor et al. 2018). The enzymes (Sigma Aldrich) were mixed fresh daily in a $0.1 \%$ Bovine Serum Albumin (Sigma Aldrich) solution to a final concentration of 100 units $/ \mathrm{mL}$ and filtered with a $0.2 \mu \mathrm{m}$ filter attached to a syringe. Mixed enzymes were protected from light and stored on ice until immediately before infusion.

\section{mPFC infusions of PEN or ChABC}

Twenty-four rats were assigned to the $\mathrm{MPFC}$ condition, with twelve receiving PEN treatment and twelve receiving ChABC treatment. PEN is a widely utilized control bacterial enzyme for ChABC treatments in studies of brain and spinal cord ECM degradation which does not cleave apart the components of CSPGs (Moon et al. 2001; Bradbury et al. 2002; Pizzorusso et al. 2002). Before the operation, injectors were made from 35 Ga silica tubing (WPI), glued to PE-50 tubing, and then set up with the stereotaxic apparatus. Prior to and throughout the procedure, rats were anesthetized with an isoflurane gas inhalant (Janssen). All rats were administered a $0.5 \mathrm{mg} /$ $\mathrm{kg}$ subcutaneous dose of the analgesic Anafen (Merial Canada Inc) prior to surgery. Once anesthetized, animals were positioned in the stereotaxic apparatus. Next, the scalp was cut with a scalpel and retracted to expose the skull. Holes were then drilled into the skull and the injectors set up with stereotaxic apparatus were inserted bilaterally at the following coordinates: anteroposterior (AP) $+3.0 \mathrm{~mm}$; lateral (L) $0.7 \mathrm{~mm}$; dorsoventral (DV) $4.4 \mathrm{~mm}$ relative to bregma. From there, either ChABC (100 units/mL) or PEN (100 units/mL) (depending on the treatment group) was infused at the DV coordinates $-4.4,-4.2$, and $-3.9 \mathrm{~mm}$. These infusions were performed at a rate of $0.1 \mu \mathrm{L}$ per minute for $2 \mathrm{~min}$ (total infusion volume of $0.6 \mu \mathrm{L} / \mathrm{side})$. Injectors were left in place for an additional 6 min to allow for diffusion of the solution away from the final infusion site (DV $=-3.9 \mathrm{~mm})$. After this time the injectors were slowly removed, the holes in the skull were filled with bone wax, and then the wound was closed with stitches.

\section{PPC infusions of PEN or ChABC}

Twenty-four rats were assigned to the PPC condition, with twelve receiving PEN treatment and twelve receiving ChABC treatment. Surgery setup and anesthetization of animals matched that of mPFC infusions. Once anesthetized, animals were positioned in the stereotaxic apparatus. Next, the scalp was cut with a scalpel and retracted to expose the skull. Holes were then drilled into the skull and the injectors set up with stereotaxic apparatus were inserted bilaterally at and anterior location and a posterior location. The anterior location had the following coordinates: AP $-3.30 \mathrm{~mm}$; L $2.80 \mathrm{~mm}$; DV $-1.20 \mathrm{~mm}$ relative to bregma. The posterior location had the following coordinates: AP $-3.80 \mathrm{~mm}$; L 3.00 $\mathrm{mm}$; DV $-1.30 \mathrm{~mm}$ relative to bregma. From there, either ChABC (100 units/mL) or PEN (100 units/mL) (depending on the treatment group) was infused at the anterior location with the DV coordinates of -1.10 and $-1.00 \mathrm{~mm}$, and at the posterior location with the DV coordinates of -1.30 and $-1.20 \mathrm{~mm}$. These infusions were performed at a rate of $0.2 \mu \mathrm{L}$ per minute for $2 \mathrm{~min}$ (total infusion volume of $0.6 \mu \mathrm{L} /$ side at the anterior location and $1.2 \mu \mathrm{L} /$ side at the posterior location). Injectors were left in place for an additional $6 \mathrm{~min}$ to allow for diffusion of the solution away from the final infusion site (anterior $\mathrm{DV}=-1.0 \mathrm{~mm}$, posterior $\mathrm{DV}=-1.20 \mathrm{~mm}$ ). After this time the injectors were slowly removed, the holes in the skull were filled with bone wax, and then the wound was closed with stitches.

\section{TUNL testing protocol}

Testing was performed between 5 to $10 \mathrm{~d}$ after surgery (Fig. 1). The first $3 \mathrm{~d}$ (testing days 1-3) of testing consisted of a standard $6 \mathrm{sec}$ delay TUNL task. This tested the effect of ChABC on the same condition that rats were trained on. The next $4 \mathrm{~d}$ of testing (testing days 4-7) consisted of a variable 2 or 6 sec delay to test delay-dependent changes in WM. The following $2 \mathrm{~d}$ (days 8-9) tested for interference, in which the delay was set to $2 \mathrm{sec}$ and the ITI period was set from 20 to $1 \mathrm{sec}$. Finally, the final $6 \mathrm{~d}$ of testing (testing days 10-15) consisted of a challenging and novel 20 sec delay period. The amount of testing days in each condition was based on the average number of selection trials performed per day within that condition. Each testing condition consisted of a total of 150-300 selection trials. One rat from the mPFC ChABC group was excluded as an outlier in each of the four conditions, as the number of selection trials that they completed in each condition was greater than two standard deviations from the mean.

\section{Tissue collection}

After behavioral testing, rats were deeply anesthetized with isofluorane. Once fully anesthetized, they were perfused with PBS followed by $4 \%$ paraformaldehyde using infusion pumps. Following perfusion, brains were extracted and stored in a sucrose azide solution $\left(30 \%\right.$ sucrose, $0.1 \%$ azide in water) at $20^{\circ} \mathrm{C}$. Next, the brains were mounted onto a chuck with optimal cutting temperature (OCT) gel and frozen using cold, pressurized carbon dioxide gas. They were then sectioned using a sliding microtome at $40 \mu \mathrm{m}$ and collected in a bath of $0.05 \mathrm{M}$ PBS. 


\section{Immunohistochemistry}

Slices were stored on slides in a $-20^{\circ}$ freezer until they were removed and thawed to room temperature $(20 \mathrm{~min})$ prior to the immunohistochemistry protocol. Slides were washed three times in $1 \times$ PBS for $10 \mathrm{~min}$ each. After this, slides were incubated with $10 \%$ Protein Block, serum-free (Dako) in $1 \times$ PBS for $1 \mathrm{~h}$. Slides were then incubated overnight with a primary antibody solution of 1\% Protein Block, 1\% Bovine Serum Albumin, and 98\% 1× PBS with $0.1 \%$ Triton X-100 detergent. Primary antibodies used were as follows: mouse anti-chondroitin-4-sulfate (C4S; 1:400; Millipore), Wisteria Floribunda Agglutinin (WFA; 1:1000; Swant), rabbit anti-Parvalbumin (PV; 1:1000; Swant). The following day, slides were again washed three times, twice in PBS $1 \times$ with $1 \%$ Tween-20 and then once in PBS $1 \times$. Slides were then incubated for $1 \mathrm{~h}$ with secondary antibodies as follows: donkey anti-mouse Alexa Fluor 488 (1:200; Invitrogen), donkey anti-rabbit Alexa Fluor 546 (1:200; Invitrogen), and Streptavidin 647 (1:200; Invitrogen). After the 1 -h secondary incubation, slides were washed three times, twice in PBS $1 \times$ with $1 \%$ Tween-20 and once with PBS $1 \times$. Slides were then labeled with 4',6-diamidino2-phenylindole (DAPI) in Vectashield mounting medium (Vector Labs) and a coverslip was placed over the slide.

\section{Widefield epifluorescence microscopy}

Images of sections were acquired on a LEICA DMI6000B Microscope using LAS AF computer software. To landmark the mPFC and PPC we used The Rat Brain in Stereotaxic Coordinates and selected based on features identified in the DAPI nuclear staining pattern (Paxinos and Watson 2007). The mPFC was imaged between +2.76 and $+3.24 \mathrm{~mm}$ anterior to bregma with the imaging window extending from the midline through cortical layers 1-6. All images for analysis were captured at 10x magnification and six images were taken per animal. Images from the somatosensory cortex were taken from within the same sections as images for the mPFC $(+2.76$ to $+3.24 \mathrm{~mm})$, to control for any variability between animals in staining intensity. The PPC was imaged between -3.84 and $-4.68 \mathrm{~mm}$ posterior to bregma with the imaging window extending from the dorsal surface of the brain through cortical layers 1-6. Within the LAS AF software, a constant gain, exposure, and light intensity was used across all animals.

\section{Image analysis}

Tissue analysis was conducted on unmodified images by an experiment blind to the experimental conditions. Staining intensity was quantified from all stains using the automated quantification software CellProfiler (Lamprecht et al. 2007) Images were loaded into the software and analyzed using the MeasureImageIntensity module. Cell numbers were counted manually using the ImageJ Cell Counter function.

\section{Statistical analyses}

All data are presented as mean \pm SEM. Statistical analyses were conducted in SPSS (IBM SPSS Statistics 25) using two-tailed independent-samples $t$-tests and repeated measures ANOVAs. Significance was set at $P<0.05$.

\section{Competing interest statement}

The authors declare no conflict of interest.

\section{Acknowledgments}

We thank Max Liu and Yuanyi Song for their assistance with this project. This research was supported by an operating grant from the Canadian Institutes for Health Research (\#125984) and Discovery Grants from the Natural Sciences and Engineering Research Council of Canada (NSERC). M.D.A. received scholarship funding from the University of Saskatchewan. J.W.P. received scholarship funding from NSERC. G.A.S. received scholarship funding from NSERC and the University of Saskatchewan.

\section{References}

Alekseichuk I, Turi Z, Amador De Lara G, Antal A, Paulus W. 2016. Spatial working memory in humans depends on theta and high gamma synchronization in the prefrontal cortex. Curr Biol 26: 1513-1521. doi:10.1016/j.cub.2016.04.035

Baig S, Wilcock GK, Love S. 2005. Loss of perineuronal net $\mathrm{N}$-acetylgalactosamine in Alzheimer's disease. Acta Neuropathologica 110: 93-401. doi: 10.1007/s00401-005-1060-2

Bradbury EJ, Moon LD, Popat RJ, King VR, Bennett GS, Patel PN, Fawcett JW, McMahon SB. 2002. Chondroitinase ABC promotes functional recovery after spinal cord injury. Nature 416: 636-640. doi:10 $.1038 / 416636 \mathrm{a}$

Brückner G, Brauer K, Härtig W, Wolff JR, Rickmann MJ, Derouiche A, Delpech B, Girard N, Oertel WH, Reichenbach A. 1993. Perineuronal nets provide a polyanionic, glia-associated form of microenvironment around certain neurons in many parts of the rat brain. Glia 8: 183-200. doi:10.1002/glia.440080306

Burnside ER, Winter FD, Didangelos A, James ND, Andreica E, Layard-Horsfall H, Muir EM, Verhaagen J, Bradbury EJ. 2018. Immune-evasive gene switch enables regulated delivery of chondroitinase after spinal cord injury. Brain 141: 2362-2381. doi:10 $.1093 /$ brain/awy158

Cabungcal JH, Steullet P, Morishita H, Kraftsik R, Cuenod M, Hensch TK, Do KQ. 2013. Perineuronal nets protect fast-spiking interneurons against oxidative stress. Proc Natl Acad Sci 110: 9130-9135. doi:10.1073/ pnas. 1300454110

Carstens KE, Phillips ML, Pozzo-Miller L, Weinberg RJ, Dudek SM. 2016. Perineuronal nets suppress plasticity of excitatory synapses on CA2 pyramidal neurons. J Neurosci 36: 6312-6320. doi:10.1523/JNEUROSCI $.0245-16.2016$

Carulli D, Pizzorusso T, Kwok JC, Putignano E, Poli A, Forostyak S, Andrews MR, Deepa SS, Glant TT, Fawcett JW. 2010. Animals lacking link protein have attenuated perineuronal nets and persistent plasticity. Brain 133: 2331-2347. doi:10.1093/brain/awq145

Chu P, Abraham R, Budhu K, Khan U, Garcia ND, Brumberg JC. 2018. The impact of perineuronal net digestion using Chondroitinase $\mathrm{ABC}$ on the intrinsic physiology of cortical neurons. Neuroscience 388: 23-35. doi:10 .1016/j.neuroscience.2018.07.004

Courtney SM, Petit L, Maisog JM, Underleider LG, Haxby JV. 1998. An area specialized for spatial working memory in human frontal cortex. Science 279: 1347-1351. doi:10.1126/science.279.5355.1347

Davies DA, Hurtubise JL, Greba Q, Howland JG. 2017. Medial prefrontal cortex and dorsomedial striatum are necessary for the trial-unique, delayed nonmatching-to-location (TUNL) task in rats: role of NMDA receptors. Learn Mem 24: 262-266. doi:10.1101/lm.044750 .116

Deepa SS, Carulli D, Galtrey C, Rhodes K, Fukuda J, Mikami T, Sugahara K, Fawcett JW. 2006. Composition of perineuronal net extracellular matrix in rat brain. J Biol Chem 281: 17789-17800. doi:10.1074/jbc .M600544200

Delatour B, Gisquet-Verrier P. 1999. Lesions of the prelimbic-infralimbic cortices in rats do not disrupt response selection processes but induce delay-dependent deficits: evidence for a role in working memory? Behav Neurosci 113: 941-955. doi:10.1037/0735-7044.113.5.941

Domínguez S, Rey CC, Therreau L, Fanton A, Massotte D, Verret L, Piskorowski RA, Chevaleyre V. 2019. Maturation of PNN and ErbB4 signaling in area CA2 during adolescence underlies the emergence of PV interneuron plasticity and social memory. Cell Rep 29: 1099-1112.e4. doi:10.1016/j.celrep.2019.09.044

Donato F, Rompani SB, Caroni P. 2013. Parvalbumin-expressing basket-cell network plasticity induced by experience regulates adult learning. Nature 504: 272-276. doi:10.1038/nature 12866

Dzyubenko E, Gottschling C, Faissner A. 2016. Neuron-glia interactions in neural plasticity: contributions of neural extracellular matrix and perineuronal nets. Neural Plast 2016: 5214961. doi:10.1155/2016/ 5214961

Enwright JF, Sanapala S, Foglio A, Berry R, Fish KN, Lewis DA. 2016. Reduced labeling of parvalbumin neurons and perineuronal nets in the dorsolateral prefrontal cortex of subjects with schizophrenia. Neuropsychopharmacology 41: 2206-2214. doi:10.1038/npp.2016.24

Eriksson J, Vogel E, Lansner A, Bergström F, Nyberg L. 2015. Neurocognitive architecture of working memory. Neuron 88: 33-46. doi:10.1016/j .neuron.2015.09.020

Franklin SL, Love S, Greene JR, Betmouni S. 2008. Loss of perineuronal net in ME7 prion disease. J Neuropathol Exp Neurol 67: 189-199. doi:10.1097/ NEN.0b013e3181654386 
Gisquet-Verrier P, Winocur G, Delatour B. 2000. Functional dissociation between dorsal and ventral regions of the medial prefrontal cortex in rats. Psychobiology 28: 248-260.

Gogolla N, Caroni P, Luthi A, Herry C. 2009. Perineuronal nets protect fear memories from erasure. Science 325: 1258-1261. doi:10.1126/science .1174146

Griffiths BB, Madden AMK, Edwards KA, Zup SL, Stary CM. 2019. Age-dependent sexual dimorphism in hippocampal cornu ammonis-1 perineuronal net expression in rats. Brain Behav 9: e01265. doi:10.1002/ brb3.1265

Happel MF, Niekisch H, Rivera LL, Ohl FW, Deliano M, Frischknecht R. 2014. Enhanced cognitive flexibility in reversal learning induced by removal of the extracellular matrix in auditory cortex. Proc Natl Acad Sci 111: 2800-2805. doi:10.1073/pnas.1310272111

Härtig W, Brauer K, Brückner G. 1992. Wisteria floribunda agglutinin-labelled nets surround parvalbumin-containing neurons. Neuroreport 3: 869-872. doi:10.1097/00001756-199210000-00012

Hayani H, Song I, Dityatev A. 2018. Increased excitability and reduced excitatory synaptic input into fast-spiking CA2 interneurons after enzymatic attenuation of extracellular matrix. Front Cell Neurosci 12: 149. doi:10.3389/fncel.2018.00149

Herremans AH, Hijzen TH, Welborn PF, Olivier B, Slangen JL. 1996. Effects of infusion of cholinergic drugs into the prefrontal cortex area on delayed matching to position performance in the rat. Brain Res 711: 102-111. doi:10.1016/0006-8993(95)01404-7

Hobohm C, Günther A, Grosche J, Rossner S, Schneider D, Brückner G. 2005. Decomposition and long-lasting downregulation of extracellular matrix in perineuronal nets induced by focal cerebral ischemia in rats. $J$ Neurosci Res 80: 539-548. doi:10.1002/jnr.20459

Hurtubise JL, Marks WN, Davies DA, Catton JK, Baker GB, Howland JG. 2017. MK-801-induced impairments on the trial-unique, delayed nonmatching-to-location task in rats: effects of acute sodium nitroprusside. Psychopharmacology (Berl) 234: 211-222. doi:10.1007/ s00213-016-4451-2

Hylin MJ, Orsi SA, Moore AN, Dash PK. 2013. Disruption of the perineuronal net in the hippocampus or medial prefrontal cortex impairs fear conditioning. Learn Mem 20: 267-273. doi:10.1101/lm .030197 .112

Josey M, Brigman JL. 2015. Loss of hippocampal function impairs pattern separation on a mouse touch-screen operant paradigm. Neurobiol Learn Mem 125: 85-92. doi:10.1016/j.nlm.2015.08.002

Kim CH, Romberg C, Hvoslef-Eide M, Oomen CA, Mar AC, Heath CJ, Berthiaume AA, Bussey TJ, Saksida LM. 2015. Trial-unique, delayed nonmatching-to-location (TUNL) touchscreen testing for mice: sensitivity to dorsal hippocampal dysfunction. Psychopharmacology (Berl) 232: 3935-3945. doi:10.1007/s00213-015-4017-8

Kumar G, Olley J, Steckler T, Talpos J. 2015. Dissociable effects of NR2A and NR2B NMDA receptor antagonism on cognitive flexibility but not pattern separation. Psychopharmacology (Berl) 232: 3991-4003. doi:10 .1007/s00213-015-4008-9

Kwok JC, Carulli D, Fawcett JW. 2010. In vitro modeling of perineuronal nets: hyaluronan synthase and link protein are necessary for their formation and integrity. J Neurochem 114: 1447-1459. doi:10.1111/j .1471-4159.2010.06878.x

Lamprecht MR, Sabatini DM, Carpenter AE. 2007. CellProfiler: free, versatile software for automated biological image analysis. BioTechniques 42: $71-$ 75. doi: $10.2144 / 000112257$

Lasek AW, Chen H, Chen W. 2018. Releasing addiction memories trapped in perineuronal nets. Trends Genet 34: 197-208. doi:10.1016/j.tig.2017.12 .004

Lee H, Mckeon RJ, Bellamkonda RV. 2009. Sustained delivery of thermostabilized chABC enhances axonal sprouting and functional recovery after spinal cord injury. Proc Natl Acad Sci 107: 3340-3345. doi:10.1073/pnas.0905437106

Lee H, Leamey CA, Sawatari A. 2012. Perineuronal nets play a role in regulating striatal function in the mouse. PLoS One 7: e32747. doi:10 .1371/journal.pone.0032747

Lensjø KK, Christensen AC, Tennøe S, Fyhn M, Hafting T. 2017a. Differential expression and cell-type specificity of perineuronal nets in hippocampus, medial entorhinal cortex, and visual cortex examined in the rat and mouse. eNeuro 4: ENEURO.0379-16.2017. doi:10.1523/ ENEURO.0379-16.2017

Lensjø KK, Lepperød ME, Dick G, Hafting T, Fyhn M. 2017b. Removal of perineuronal nets unlocks juvenile plasticity through network mechanisms of decreased inhibition and increased gamma activity. J Neurosci 37: 1269-1283. doi:10.1523/JNEUROSCI.2504-16 .2016

Lins BR, Phillips AG, Howland JG. 2015. Effects of D- and L-govadine on the disruption of touchscreen object-location paired associates learning in rats by acute MK-801 treatment. Psychopharmacology (Berl) 232: 43714382. doi:10.1007/s00213-015-4064-1
Mackey WE, Devinsky O, Doyle WK, Golfinos JG, Curtis CE. 2016. Human parietal cortex lesions impact the precision of spatial working memory. $J$ Neurophysiol 116: 1049-1054. doi:10.1152/jn.00380.2016

Mauney SA, Athanas KM, Pantazopoulos H, Shaskan N, Passeri E, Berretta S, Woo TW. 2013. Developmental pattern of perineuronal nets in the human prefrontal cortex and their deficit in schizophrenia. Biol Psychiatry 74: 427-435. doi:10.1016/j.biopsych.2013.05.007

McAllister KA, Saksida LM, Bussey TJ. 2013. Dissociation between memory retention across a delay and pattern separation following medial prefrontal cortex lesions in the touchscreen TUNL task. Neurobiol Learn Mem 101: 120-126. doi:10.1016/j.nlm.2013.01.010

McRae PA, Porter BE. 2012. The perineuronal net component of the extracellular matrix in plasticity and epilepsy. Neurochem Int 61: 963972. doi:10.1016/j.neuint.2012.08.007

Moon LD, Asher RA, Rhodes KE, Fawcett JW. 2001. Regeneration of CNS axons back to their target following treatment of adult rat brain with chondroitinase ABC. Nat Neurosci 4: 465-466. doi:10.1038/ 87415

Morawski M, Brückner MK, Riederer P, Brückner G, Arendt T. 2004. Perineuronal nets potentially protect against oxidative stress. Exp Neurol 188: 309-315. doi:10.1016/j.expneurol.2004.04.017

Morellini F, Sivukhina E, Stoenica L, Oulianova E, Bukalo O, Jakovcevski I, Dityatev A, Schachner M. 2010. Improved reversal learning and working memory and enhanced reactivity to novelty in mice with enhanced GABAergic innervation in the dentate gyrus. Cereb Cortex 20: 27122727. doi: $10.1093 /$ cercor/bhq017

Morishita H, Cabungcal J, Chen Y, Do KQ, Hensch TK. 2015. Prolonged period of cortical plasticity upon redox dysregulation in fast-spiking interneurons. Biol Psychiatry 78: 396-402. doi:10.1016/j.biopsych.2014 .12 .026

Narayanan N, Horst N, Laubach M. 2006. Reversible inactivations of rat medial prefrontal cortex impair the ability to wait for a stimulus. Neuroscience 139: 865-876. doi:10.1016/j.neuroscience.2005.11.072

Paxinos G, Watson C. 2007. The rat brain in stereotaxic coordinates. Elsevier Academic Press, London, United Kingdom.

Paylor JW, Lins BR, Greba Q, Moen N, Moraes RS, Howland JG, Winship IR. 2016. Developmental disruption of perineuronal nets in the medial prefrontal cortex after maternal immune activation. Sci Rep 6: 37580. doi: $10.1038 /$ srep37580

Paylor JW, Wendlandt E, Freeman TS, Greba Q, Marks WN, Howland JG, Winship IR. 2018. Impaired cognitive function after perineuronal net degradation in the medial prefrontal cortex. eNeuro 5: ENEURO.0253-18.2018. doi:10.1523/ENEURO.0253-18.2018

Pizzorusso T, Medini P, Berardi N, Chierzi S, Fawcett JW, Maffei L. 2002. Reactivation of ocular dominance plasticity in the adult visual cortex. Science 298: 1248-1251. doi:10.1126/science.1072699

Romberg C, Yang S, Melani R, Andrews MR, Horner AE, Spillantini MG, Bussey TJ, Fawcett JM, Pizzorusso T, Saksida LM. 2013. Depletion of perineuronal nets enhances recognition memory and long-term depression in the perirhinal cortex. J Neurosci 33: 7057-7065. doi:10 $.1523 /$ JNEUROSCI.6267-11.2013

Scott GA, Roebuck AJ, Greba Q, Howland JG. 2019. Performance of the trial-unique, delayed non-matching-to-location (TUNL) task depends on AMPA/Kainate, but not NMDA, ionotropic glutamate receptors in the rat posterior parietal cortex. Neurobiol Learn Mem 159: 16-23. doi:10 .1016/j.nlm.2019.02.001

Seeger G, Brauer K, Härtig W, Brückner G. 1994. Mapping of perineuronal nets in the rat brain by colloidal iron hydroxide histochemistry and lectin cytochemistry. Neuroscience 58: 371-388. doi:10.1016/0306-4522 (94) $90044-2$

Shen HH. 2018. Core Concept: perineuronal nets gain prominence for their role in learning, memory, and plasticity. Proc Natl Acad Sci 115: 98139815. doi:10.1073/pnas.1815273115

Slaker M, Churchill L, Todd RP, Blacktop JM, Zuloaga DG, Raber J, Darling RA, Brown TE, Sorg BA. 2015. Removal of perineuronal nets in the medial prefrontal cortex impairs the acquisition and reconsolidation of a cocaine-induced conditioned place preference memory. J Neurosci 35: 4190-4202. doi:10.1523/JNEUROSCI.3592-14.2015

Sorg BA, Berretta S, Blacktop JM, Fawcett JW, Kitagawa H, Kwok JC, Miquel M. 2016. Casting a wide net: role of perineuronal nets in neural plasticity. J Neurosci 36: 11459-11468. doi:10.1523/JNEUROSCI.235116.2016

Stephenson EL, Zhang P, Ghorbani S, Wang A, Gu J, Keough MB, Rawji KS, Silva C, Yong VW, Ling CC. 2019. Targeting the chondroitin sulfate proteoglycans: evaluating fluorinated glucosamines and xylosides in screens pertinent to multiple sclerosis. ACS Cent Sci 5: 1223-1234. doi:10 1021 acscentsci.9b00327

Talpos JC, McTighe SM, Dias R, Saksida LM, Bussey TJ. 2010. Trial-unique, delayed nonmatching-to-location (TUNL): a novel, highly hippocampus-dependent automated touchscreen test of location memory and pattern separation. Neurobiol Learn Mem 94: 341-352. doi:10.1016/j.nlm.2010.07.006 
Thompson EH, Lensjø KK, Wigestrand MB, Malthe-Sørenssen A, Hafting T, Fyhn M. 2018. Removal of perineuronal nets disrupts recall of a remote fear memory. Proc Natl Acad Sci 115: 607-612. doi:10.1073/pnas .1713530115

Todd JJ, Marois R. 2004. Capacity limit of visual short-term memory in human posterior parietal cortex. Nature 428: 751-754. doi:10.1038/ nature02466

Yamada J, Jinno S. 2013. Spatio-temporal differences in perineuronal net expression in the mouse hippocampus, with reference to parvalbumin. Neuroscience 253: 368-379. doi:10.1016/j.neuroscience .2013.08.061

Xue YX, Xue LF, Liu JF, He J, Deng JH, Sun SC, Han HB, Luo YX, Xu LZ, Wu P, et al. 2014. Depletion of perineuronal nets in the amygdala to enhance the erasure of drug memories. J Neurosci 34: 6647-6658. doi:10.1523/ JNEUROSCI.5390-13.2014

Received June 29, 2019; accepted in revised form February 27, 2020. 


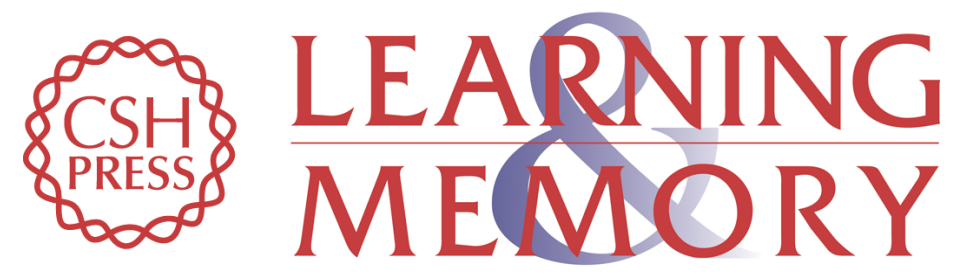

\section{ChABC infusions into medial prefrontal cortex, but not posterior parietal cortex, improve the performance of rats tested on a novel, challenging delay in the touchscreen TUNL task}

Michael D. Anderson, John W. Paylor, Gavin A. Scott, et al.

Learn. Mem. 2020, 27:

Access the most recent version at doi:10.1101//m.050245.119

References This article cites 64 articles, 19 of which can be accessed free at: http://learnmem.cshlp.org/content/27/6/222.full.html\#ref-list-1

Creative This article is distributed exclusively by Cold Spring Harbor Laboratory Press for the Commons first 12 months after the full-issue publication date (see

License http://learnmem.cshlp.org/site/misc/terms.xhtml). After 12 months, it is available under a Creative Commons License (Attribution-NonCommercial 4.0 International), as described at http://creativecommons.org/licenses/by-nc/4.0/.

Email Alerting Receive free email alerts when new articles cite this article - sign up in the box at the Service top right corner of the article or click here. 